\title{
A Robust Protocol for Regional Evaluation of Methacholine Challenge in Mouse Models of Allergic Asthma Using Hyperpolarized ${ }^{3} \mathrm{He}$ MRI
}

\author{
Abraham C. Thomas ${ }^{1}$, Erin N. Potts ${ }^{2}$, Ben T. Chen ${ }^{3}$, Deborah M. Slipetz ${ }^{4}$, W. Michael \\ Foster $^{2}$, and Bastiaan Driehuys ${ }^{1}$ \\ ${ }^{1}$ Center for In Vivo Microscopy, Dept. of Radiology, Duke University Medical Center, Durham, NC, \\ USA \\ ${ }^{2}$ Division of Pulmonary, Allergy, and Critical Care Medicine, Duke University Medical Center, \\ Durham, NC, USA \\ ${ }^{3}$ Department of Imaging, Merck \& Co., Inc., Rahway, NJ, USA \\ ${ }^{4}$ Department of Pharmacology, Merck Frosst Centre for Therapeutic Research, Kirkland, QC, \\ Canada
}

\section{Abstract}

Hyperpolarized ${ }^{3} \mathrm{He}$ magnetic resonance imaging (MRI) NEED TO INTRODUCE TERM, UNLESS YOU ARE OVER THE WORD COUNThas been recently used to produce high-resolution images of pulmonary ventilation after methacholine challenge in mouse models of allergic inflammation. This capability presents an opportunity to gain new insights about these models and to more sensitively evaluate new drug treatments in the pre-clinical setting. In the current study, we present our initial experience using two-dimensional, time-resolved ${ }^{3} \mathrm{He}$ MRI of methacholine challengeinduced airways hyperreactivity to compare ovalbumin-sensitized and challenged $(\mathrm{N}=8)$ mice to controls $(\mathrm{N}=8)$. Imaging demonstrated that ovalbumin-sensitized and challenged animals exhibited many large ventilation defects even prior to methacholine challenge (4 out of 8) compared to no defects in the control animals. Additionally, the ovalbumin sensitized and challenged animals experienced a greater number of ventilation defects $(4.5 \pm 0.4)$ following methacholine infusion than did controls $(3.3 \pm 0.6)$. However, due to variability in methacholine delivery that was specific to the small animal MRI environment, the difference in mean defect number was not statistically significant. These findings are reviewed in detail and a comprehensive solution to the variability problem is presented that has greatly enhanced the magnitude and reproducibility of the methacholine response. This has permitted us to develop a new imaging protocol consisting of a baseline 3D image, a time-resolved 2D series during methacholine challenge, and a post-methacholine 3D image that reveals persistent ventilation defects.

\section{Keywords}

hyperpolarized; ${ }^{3} \mathrm{He} \mathrm{MRI}$; bronchoconstriction; ovalbumin; methacholine; asthma; mice

Correspondence: Bastiaan Driehuys, Center for In Vivo Microscopy, Box 3302, Duke University Medical Center, Durham, NC 27710, (TEL) 919-684-7786, (FAX) 919-684-7122, (E-mail) E-mail: bastiaan.driehuys@ duke.edu. 


\section{Introduction}

Hyperpolarized (HP) ${ }^{3} \mathrm{He}$ magnetic resonance imaging (MRI) is a novel, non-invasive technique that enables pulmonary ventilation to be directly visualized with high spatial resolution(1,2). Compared to conventional pulmonary function testing, HP gas MRI has the potential to greatly enhance detection sensitivity by adding regional context to the functional information obtained(3). In particular, HP ${ }^{3} \mathrm{He}$ MRI has been applied successfully to patients with asthma and reveals that they exhibit numerous regions where ventilation is impaired or non-existent(4). These have been referred to as "ventilation defects" and have been shown to correlate with the severity of asthma(3). Ventilation defects can be provoked in even larger number by challenging the patient with aerosolized methacholine $(\mathrm{MCh})(5)$. MCh challenge is commonly used in diagnosing patients with suspected asthma(6), and hence, the ability to directly visualize changes in a patient's regional ventilation in response to this diagnostic test is of particular interest in asthma research.

Given the power of ${ }^{3} \mathrm{He}$ MRI to impact clinical asthma research, it is increasingly important to translate this technology and apply it to small animal models of asthma. In particular, the mouse has become an important component of asthma research and drug development efforts. In mice, - a wide availability of models of allergic lung inflammation -mimic some of the pathophysiology of human asthma, and these animals can be genetically manipulated to evaluate specific pathways and genes involved in the disease(7). As in the clinic, it is important to be able to visualize changes in murine ventilation that occur in response to MCh challengeinduced airways hyperreactivity (AHR). MCh challenge is essential in conventional physiologic phenotyping of the mouse by respiratory mechanics(8). Although remarkable gains and insights have been made using respiratory mechanics in conjunction with sophisticated modeling, there is little dispute that these methods are limited in their capacity to reveal functional heterogeneity or unambiguously explain the observed resistance in terms of exact pulmonary behavior(9-11). This problem is ideally addressed by ${ }^{3} \mathrm{He}$ MRI and to this end, we recently demonstrated its use to visualize the altered ventilation distribution in the lungs of mice challenged with $\mathrm{MCh}(12)$. This preliminary work used an ovalbumin allergen sensitization/challenge model of allergic inflammation(7) and demonstrated a marked ventilation redistribution after MCh challenge occurring within seconds of MCh challenge and largely recovering after several minutes.

A critical next step in demonstrating the value of ${ }^{3} \mathrm{He} \mathrm{MRI}$ in studying mouse models of allergic inflammation is to apply the technique to a variety of treatment groups in anticipation that ${ }^{3} \mathrm{He}$ MRI might better differentiate such groups than conventional methods. Such a comparison requires the development of a robust protocol whereby the differences between treated and control groups can be illuminated. In this paper, we describe our initial experience with a protocol focused on using two-dimensional (2D) imaging of the temporal dynamics of $\mathrm{MCh}$ response in ovalbumin-sensitized and control animals. This preliminary work yielded a number of notable differences in the ventilation patterns of the two groups before and after MCh challenge, but also exposed difficulties in reliably delivering MCh in the small animal MRI environment. Thus, we also describe our investigation of the MCh delivery problem and the new methods we have developed to overcome it. We summarize the report with a preliminary demonstration of our revised protocol, which in addition to making the MCh delivery robust, now also adds $3 \mathrm{D}$ imaging before and after $\mathrm{MCh}$ challenge to the $2 \mathrm{D}$ timecourse imaging to permit evaluation of both short-time airway response and more persistent ventilation defects. 


\section{Experimental}

\section{1 Ovalbumin Sensitization}

All aspects of the animal welfare and experimentation were approved by the Duke University Institutional Animal Care and Use Committee. All studies used 6-8 week old male Balb/C mice (Jackson Labs, Bar Harbor, ME) in three groups: naïve, allergic inflammation, or control. The allergic inflammation group was sensitized with ovalbumin and subsequently challenged with ovalbumin, whereas control mice were ovalbumin-sensitized, and challenged with only phosphate buffered saline (PBS). We refer to these groups as Ova/Ova and Ova/PBS, respectively, and they were prepared as described by Therien et al.(13) with the following modifications. Mice were sensitized with an intraperitoneal (i.p.) injection of $20 \mu \mathrm{g}$ ovalbumin (Ova) adsorbed to $2 \mathrm{mg}$ of alum adjuvant on day 0 and then again on day 7 with $10 \mu \mathrm{g}$ Ova adsorbed to $1 \mathrm{mg}$ of alum. The mice were subsequently challenged with either aerosolized Ova or PBS for $20 \mathrm{~min}$ in a whole-body exposure chamber on days 14,15 , and 16 . The Ova aerosol consisted of 5\% Ova in 1X PBS and the control aerosol consisted of PBS only. Ova/PBS treatment is the preferred way to generate a control group to ensure that both groups experience the same treatments except for the aerosol challenge(7). Because the Ova/Ova model of allergic asthma is acute(14), all imaging or physiologic measurements were conducted immediately following this protocol on day 17 .

\subsection{Respiratory Mechanics and Bronchoalveolar Lavage (BAL)}

The Ova/Ova and Ova/PBS mice were characterized using the standard metrics of increased MCh-induced AHR and BAL inflammation. Specifically, 3 Ova/Ova and 3 Ova/PBS mice were used for respiratory mechanics measurements, and 9 Ova/Ova and $3 \mathrm{Ova} / \mathrm{PBS}$ mice were used for BAL to determine differential cell counts.

Total lung resistance in response to $\mathrm{MCh}$ challenge were measured using the flexiVent system (flexiVent, SCIREQ, Montreal, Canada), which uses a low-frequency forced oscillation technique to determine ventilation parameters. These include dynamic respiratory system Resistance (R), Elastance (E) and Compliance $(C=1 / E)$, which are measured by delivering a standardized sinusoidal breath waveform while recording the associated airway pressures. Mice were anesthetized and then tracheotomized with a cannula for connection to a small animal ventilator, which permits the application of volume perturbations to the lungs. A positive end-expiratory pressure of $3 \mathrm{~cm} \mathrm{H}_{2} \mathrm{O}$ was usedand airway pressure (side arm of the tracheal cannula) and tidal volume data were generated by the application of a 2-s sine wave volume perturbation with an amplitude of $0.2 \mathrm{ml}$ and a frequency of $2.5 \mathrm{~Hz}$. During measurements, MCh was delivered at a concentration of $80 \mu \mathrm{g} / \mathrm{ml}$ by jugular i.v. injection to maintain consistency with the delivery route and concentration used for ${ }^{3} \mathrm{He}$ MRI studies. Additionally, due to interest in prolonging the MCh response during long-lasting 3D MRI studies, we tested delivery of MCh by infusion, as well as by the more commonly used bolus injection. Thus, airway resistance measurements were made with MCh infusions of $0.3,0.6$, and $1.2 \mathrm{~mL} / \mathrm{hr}$ administered over a period of $2 \mathrm{~min}$, corresponding to total doses of 32, 64, 96, and $128 \mu \mathrm{g} / \mathrm{kg}$ for a $25 \mathrm{~g}$ mouse. These were compared to a single $80 \mu \mathrm{g} / \mathrm{kg}$ dose administered by bolus injection in $3 \mathrm{~s}$.

\subsection{Animal Preparation for MR Imaging}

Mice were anesthetized with an $85 \mathrm{mg} / \mathrm{kg}$ i.p. dose of pentobarbital (Nembutal Sodium Solution, OVATION Pharmaceuticals, Inc., Deerfield, IL) and anesthesia was maintained with doses of $20 \mathrm{mg} / \mathrm{kg}$ pentobarbital delivered approximately every 45-60 min or when the heart rate - increased above 500 beats per minute (bpm). 
Mice were prepared for ventilation by inserting a low dead volume $(\sim 50 \mu \mathrm{L})$ tracheostomy tube below the cricoid cartilage and advancing it $5 \mathrm{~mm}$ to provide a sufficient anchor, while ensuring that the tip remained above the carina. The tracheostomy tube was created by cutting a $2.5 \mathrm{~cm}$ section from the tip of an $18 \mathrm{G}$ catheter (Hospira, Inc., Lake Forest, IL, USA).For MCh delivery, a 2F catheter (Sherwood Medical, Tullamore, Ireland) was placed in the jugular vein. The animal was placed on a custom HP gas and MR-compatible ventilator( $(15,16)$ and ventilated at 100 breaths per minute with each cycle consisting of a $240 \mathrm{~ms}$ inspiration, $100 \mathrm{~ms}$ breath-hold for image acquisition, and $260 \mathrm{~ms}$ exhalation period. The animal's temperature was measured by rectal temperature probe and this was fed back to a system circulating warm air through the magnet bore to keep the animal at $37^{\circ} \mathrm{C}$. Additional physiologic monitoring consisted of measuring HR from electrocardiogram (ECG) readings and peak inspiratory pressure (PIP), which were recorded by custom LabVIEW 8.1 (National Instruments Corporation, Austin, TX, USA) software that also controlled the ventilator timing. The animal was then placed on a cradle that fit into an $85.1 / 64.8 \mathrm{MHz}$ dual-tuned ${ }^{1} \mathrm{H} /{ }^{3} \mathrm{He}$ birdcage coil ( $L=5.5 \mathrm{~cm}, \phi=3.5 \mathrm{~cm}$ ) with the lungs positioned in the center of the coil.

\subsection{Image Acquisition}

$\mathrm{HP}^{3} \mathrm{He}$ imaging was performed at $64.8 \mathrm{MHz}$ in a $2.0 \mathrm{~T}$ horizontal $15 \mathrm{~cm}$ clear bore magnet (Oxford Instruments, Oxford, UK) with shielded gradients $(18 \mathrm{G} / \mathrm{cm})$, controlled by a GE EXCITE 12 console. ${ }^{3} \mathrm{He}$ (Spectra Gases, Alpha, NJ) was polarized to approximately $30 \%$ in batches of 1.2 liters using a prototype commercial polarizer (IGI.9600.He, MITI, Durham, $\mathrm{NC}$ ). After hyperpolarization was stopped, the $\mathrm{HP}{ }^{3} \mathrm{He}$ in the optical cell decayed with a relaxation time $\mathrm{T}_{1}=30 \mathrm{hr}$, ensuring that polarization dropped no lower than $26 \%$ over the course of a $4 \mathrm{hr}$ study.

Two-dimensional ${ }^{3} \mathrm{He}$ imaging used a radial acquisition(12) with $\mathrm{FOV}=2.4 \times 2.4 \mathrm{~cm}^{2}$ and $128 \times 128$ matrix to give a Nyquist-limited resolution of $188 \times 188 \mu \mathrm{m}^{2}$. Images were acquired using TR/TE $=5-10 / 0.3 \mathrm{~ms}$ and $\mathrm{BW}=31.25 \mathrm{kHz}$ and only during the $100 \mathrm{~ms}$ breath-hold period of the ventilatory cycle. During each breath-hold 10-20 k-space views were acquired, thus requiring $20-40$ breaths (12-24 s) to fully sample the image with 400 radial views. During each breath, the flip angle was incremented using a variable flip angle scheme ending in a $90^{\circ}$ pulse to both maximize the use of polarization and highlight the airways. Because the final $90^{\circ}$ pulse destroys all residual ${ }^{3} \mathrm{He}$ magnetization in each breath, this ensures that imaging captures the gas distribution that is achieved in a single breath. Since gas is fully replenished in the major airways in each breath, but only partially in the distal lung(17), the airway signal intensity is higher.

Three-dimensional images were acquired again using a radial trajectory(18) with field of view (FOV) of $2.0 \times 2.0 \times 3.2 \mathrm{~cm}$ and the matrix was $128 \times 128 \times 32$ for a resolution of $156 \times 156 \times 1000$ $\mu^{3}$. The 3D images required 11512 radial views for full sampling and were acquired with $\mathrm{TR}=5 \mathrm{~ms}$, thus capturing 20 views per breath and taking $5.75 \mathrm{~min}$ to complete.

\subsection{Methacholine Delivery for MR Imaging}

Methacholine (MCh) solution $(80 \mu \mathrm{g} / \mathrm{mL}$ in $0.9 \%$ saline) was prepared fresh each day from MCh powder that had been stored in the dark at $-20{ }^{\circ} \mathrm{C}$ in a desiccator. MCh solution was then stored in the dark and on ice and was only removed from storage several minutes before starting ${ }^{3} \mathrm{He}$ image acquisition. MCh solution was delivered to the mouse by syringe pump to provide optimal control over MCh volume and rate. However, because the syringe pump contains ferromagnetic materials, it must be kept at a safe distance from the MRI scanner, which in our case was 1 meter. With the animal in the center of the magnet, roughly 1 meter from the edge, the MCh solution therefore had to be delivered through 2 meters of PE50 extension tubing from pump to jugular catheter. This issue is unique to the MRI experiment 
relative to conventional physiology and required devising methods to 'prime' the extension tubing to ensure that MCh could be delivered on-demand during the MRI study. Therefore MCh solution had to be advanced through the $2 \mathrm{~m}$ extension tubing and into the jugular catheter such that the $80 \mu \mathrm{g} / \mathrm{ml}$ solution was present at the catheter tip. This aspect of the experiment was carried out according to an initial protocol (described below) that was used for the majority of the studies reported here. However, this protocol was ultimately found to result in unreliable MCh delivery and was replaced with an improved protocol that is also described.

2.5a Initial Protocol for Methacholine Delivery-MCh solution was first advanced at a rate of $1 \mathrm{~mL} / \mathrm{min}$ through the 2 meter saline-filled extension tubing without being attached to the jugular catheter to fully flush and fill the tubing. Then, the extension tubing was connected to the jugular catheter and $\mathrm{MCh}$ was pumped at $0.3 \mathrm{~mL} / \mathrm{min}$ for approximately 1 minute until MCh reached the animal. MCh-advancement was halted when a drop in heart rate of $10 \%$ below baseline (i.e., at least $50 \mathrm{bpm}$ ) was detected on the ECG monitor. The animal was then allowed to recover for 1-2 min after this initial MCh exposure and given a total lung capacity (TLC) breath, after which ${ }^{3} \mathrm{He}$ imaging could commence.

2.5b Improved Protocol for Methacholine Delivery-An improved protocol for MCh delivery was developed to specifically address the variable $\mathrm{MCh}$ response that was discovered using the initial protocol (see results). This variability was hypothesized to stem from two factors. The first was potential clotting of the jugular catheter during the relatively long time $(\sim 1 \mathrm{hr})$ from catheter insertion to its use in imaging. The second was the apparently decaying potency of the dilute $\mathrm{MCh}$ solution in the tubing near the jugular catheter. To prevent potential clotting of the MCh delivery catheter, its $50 \mu \mathrm{l}$ volume was filled with $0.1 \%$ heparinized saline prior to insertion in the jugular vein. To address the $\mathrm{MCh}$ decay, the extension line and jugular catheter were frequently flushed and their contents replaced with fresh MCh solution. Furthermore, prior to image acquisition for each animal, we first established that a robust, and consistent response to MCh could be elicited as measured by the ECG signal(19).

As shown in Figure 1, a three-way valve was inserted between the 2 meter extension tubing and the jugular catheter. This valve could be switched to periodically exhaust the entire contents of the extension tubing and replace it with fresh MCh solution. Subsequently, the valve was switched and, $\sim 200 \mu \mathrm{L}$ bolus of fresh MCh solution was delivered through the short catheter inlet tubing to displace the old MCh and provide an additional $50 \mu \mathrm{L}$ to account for mixing.

Since this flush did result in challenging the mouse with MCh (albeit with degraded MCh), the animal was permitted to recover for $2 \mathrm{~min}$ and then received a TLC breath. To ensure that MCh delivery was reliable, each animal received subsequent $125 \mu \mathrm{g} / \mathrm{kg}$ boluses of $3 \mathrm{~s}$ (with delay and recovery) until a reproducible drop in heart rate was achieved (typically $300 \mathrm{bpm}$ ). Then ${ }^{3} \mathrm{He}$ MRI was initiated immediately afterwards. The process of refreshing the MCh solution in the extension tubing and verifying heart-rate drop was carried out every 30-60 minutes, if necessary.

\subsection{Initial Imaging Protocol}

Our initial protocol focused on capturing the temporal dynamics of $\mathrm{MCh}$ response in the sensitized and control animals with a series of $2 \mathrm{D}{ }^{3} \mathrm{He}$ images acquired every $12-24 \mathrm{~s}$ for 10 successive images. Under this protocol, we evaluated 5 naïve mice, 8 Ova/Ova mice, and 5 Ova/PBS mice. Just prior to ${ }^{3} \mathrm{He}$ imaging, MCh solution was advanced to the jugular catheter tip according to our initial method (2.5a) described previously. Then, ${ }^{3} \mathrm{He}$ was dispensed from the polarizer into a $250 \mathrm{~mL}$ Tedlar (Jensen Inert Products, Coral Springs, FL, USA) bag in the ventilator reservoir and HP gas imaging was initiated. First, a baseline (pre-MCh) image was acquired and as soon as it was complete, the syringe pump was started to deliver MCh by infusion or bolus. Bolus injections were delivered in a $3 \mathrm{~s}$ period in doses ranging from 61 to 
$640 \mu \mathrm{g} / \mathrm{kg}$. Infusions were delivered for $144 \mathrm{~s}$ ( 6 image frames) and were then halted to capture $3{ }^{3} \mathrm{He}$ frames of recovery. The infusion experiments used flow rates of $0.3,0.6,0.9$, and 1.2, $2.4,3.6$ and $4.8 \mathrm{~mL} / \mathrm{hr}$, corresponding to MCh doses ranging from 46 to $742 \mu \mathrm{g} / \mathrm{kg}$ for a $25 \mathrm{~g}$ mouse. A complete listing of MCh doses delivered to each animal is displayed in Table 1.

\subsection{Final Imaging Protocol}

A final, more comprehensive protocol was developed to include both 3D and the 2D temporal series data and used the improved methods for MCh delivery described in Section 2.5b. This protocol was applied to $3 \mathrm{Ova} / \mathrm{PBS}$ animals and $6 \mathrm{Ova} / \mathrm{Ova}$ animals. Before any MCh delivery or set-up, roughly $100 \mathrm{~mL}$ of ${ }^{3} \mathrm{He}$ was dispensed into a $150 \mathrm{~mL}$ Tedlar bag in a reservoir and this gas was used to obtain a baseline (pre-MCh) 3D image. After this, the MCh solution was advanced to the jugular catheter as described in Section 2.5b.SAME COMMENT Then, a second, larger volume of $\mathrm{HP}^{3} \mathrm{He}$ was dispensed into a $250 \mathrm{~mL}$ Tedlar bag in a separate reservoir. This volume was used to generate a $2 \mathrm{D}$ time-course series with a $125 \mu \mathrm{g} / \mathrm{kg} \mathrm{MCh}$ bolus given after the first frame. Each frame was acquired in $12 \mathrm{~s}$ (by acquiring $20 \mathrm{k}$-space views per breath with $\mathrm{TR}=5 \mathrm{~ms}$ ), and 10 such images were taken. Immediately after this series, which consumed about $80 \mathrm{ml}$ of $\mathrm{HP}^{3} \mathrm{He}$, the remaining $\mathrm{HP}{ }^{3} \mathrm{He}$ volume was used, without giving another MCh bolus, to obtain a 3D post-MCh image that could be used to study the persistence of ventilation defects at high resolution.

\subsection{Data Analysis}

Data analysis for both protocols focused on the 2D time-course series following MCh challenge, with particular emphasis on the baseline pre-MCh image and the post-MCh image showing the greatest amount of response. Images were visually inspected to identify bronchoconstriction and ventilation defects. All image visualization and analysis was performed using ImageJ software version 1.38x (NIH, Bethesda, MD, USA, http://rsb.info.nih.gov/ij/).

Bronchoconstriction was determined by measuring the diameter of the most proximal portion of the medial lobe and dividing it by its diameter in the pre-MCh image. The medial lobe bronchus was chosen for its conspicuity on all images and because it appeared to be among the most responsive airways in all animals. The ratio of pre-to-post diameters was subtracted from one to give a measure of fractional bronchoconstriction.

Ventilation defects were assessed by type, number, and area. Defects were visually identified as areas of lung showing decreased intensity relative to known ventilation patterns from a series of control mice. Each defect was further quantified by tracing the defect perimeter and calculating its area. Defects were also classified as those where an entire lobe was unventilated, referred to as whole lobar defects, and those appearing at the fissure between lobes, named fissure defects. Finally, the number of ventilation defects was counted for each lobe. To properly assign ventilation defects on the $2 \mathrm{D}$ projection images to the associated lung lobe, we used a $3 \mathrm{D}$ high-resolution ${ }^{3} \mathrm{He}$ set of images previously acquired to help visualize the 5 lobes as they appear on a 2D image. This mapping is shown in Figure 2.

\section{Results}

\subsection{FlexiVent and BAL Results}

Airway cytology and physiology measurements confirmed allergic inflammation in concordance with expectations from literature sources(20). Ova/Ova animals displayed prominent eosinophilia $(20,000$ cells $/ \mathrm{mL})$ compared to the Ova/PBS control $(0$ cells $/ \mathrm{mL})$ (Figure 3A). Airway resistance as a function of MCh dose is shown in Figure 3B and 3C for Ova/Ova and Ova/PBS animals, respectively. In Ova/Ova animals after MCh challenge, peak 
airway resistance was 6-fold higher than in control mice. Comparing the bolus versus infusion delivery of MCh in Ova/Ova animals, we note that bolus injection induced a 12-fold larger increase in peak airway resistance compared to equivalent total dose delivered by infusion at $0.6 \mathrm{~mL} / \mathrm{hr}$ (Figure 3). In fact, even the highest infusion rate of $1.2 \mathrm{~mL} / \mathrm{hr}$, which was equivalent to twice the total bolus dose, resulted in a lower peak airway resistance than that achieved by bolus injection. While the infusion did appear to maintain a longer plateau of increased airway resistance, the overall magnitude of the response was quite attenuated.

\subsection{Image Findings from Initial Protocol}

Among the notable findings of our initial imaging protocol was that 4 out of $8 \mathrm{Ova} /$ Ova mice exhibited ventilation defects even prior to MCh challenge (Figure 4). By contrast, such baseline defects were not common in Ova/PBS animals, and were only seen in one control animal that was evaluated during the initial stages of the imaging and ventilation protocol development. Of the Ova/Ova mice exhibiting pre-MCh defects, 3 out of 8 had whole lobar defects, and 1 out of 8 had fissure defects. Interestingly, all of the whole lobar baseline defects in the Ova/ Ova mice were localized to the cranial lobe. The fissure defects identified in this study were a novel finding and were characterized by decreased signal adjacent to the fissures between lobes that cause them to appear especially darkened and prominent (Figure 4).

Figure 5 exhibits a typical 2D time-course series acquired in an Ova/Ova animal showing the pre-MCh image, followed by a series of images taken after $250 \mu \mathrm{g} / \mathrm{kg}$ bolus MCh challenge. The post-MCh images are characterized by bronchoconstriction of all major bronchi and a ventilation defect that occupies half of the cranial lobe. The cranial lobe ventilation defect persisted throughout the 2D time-course, even though bronchoconstriction had diminished dramatically within $36 \mathrm{~s}$ after MCh challenge. The cranial lobe bronchus became progressively more visible after the $3^{\text {rd }}$ image frame $(24 \mathrm{~s}$ post-MCh), although this did not result in increased ventilation of the cranial lobe parenchyma. The greatest $\mathrm{MCh}$ response in this series is also shown in the $3^{\text {rd }}$ image frame acquired $24 \mathrm{~s}$ after MCh challenge.

As shown in Figure 6, MCh challenge provoked bronchoconstriction and ventilation defects in mice. The various defects were noted in both Ova/Ova and Ova/PBS animals. The number of ventilation defects was somewhat greater in the Ova/Ova animals $(4.5 \pm 0.4)$ than control animals (3.3 \pm 0.6 ) (Figure 7), but not by a statistically significant margin. The analysis of ventilation defects by type was also performed (Figure 7). This shows that animals from both groups exhibited whole lobar defects post-MCh, but such defects were especially prominent in Ova/Ova animals (5 out of 8 ) compared to control animals (1 out of 8). Both groups did show similar numbers of fissure defects ( 3 defects in Ova/Ova mice and 2 defects in Ova/PBS mice) after MCh challenge. This may indicate that fissure defects primarily represent a shortterm change in peripheral ventilation that can be induced by bronchoconstriction alone as opposed to underlying changes in bronchial smooth muscle tone or airway wall inflammation and airway closure.

Analysis of pre- and post-MCh ventilation defects on a lobe-by-lobe basis is shown in Figure 8. Here, mean defect area is shown as a percentage of total lung area and assigned to the lobe of origin. Ova/PBS mice showed virtually no pre-MCh defects and exhibited a majority of post-MCh defects in the left and medial lobes. The one pre-MCh ventilation defect noted in an Ova/PBS mouse was small ( $0.2 \%$ of total lung area per mouse) compared to baseline defects in Ova/Ova mice (3.2\% of total lung area per mouse). However, Ova/Ova mice exhibited significant pre-MCh ventilation defects that were all localized to the left and cranial lobes. These lobes also showed the most significant ventilation loss post-MCh, suggesting that their associated bronchi were potentially more sensitized than other lobes. 


\subsection{Variability of MCh Response Under Initial Protocol}

The studies conducted under our initial protocol revealed considerable variability in MChresponse. Although on average, the Ova/Ova animals showed more defects and greater bronchoconstriction, there were numerous cases where Ova/PBS animals displayed markedly more dramatic MCh response than the Ova/Ova mice (Figure 9A).

Another example of unexpected variability in MCh response was found when comparing multiple MCh challenges within individual animals. For example, some mice challenged with an initial MCh dose $(186 \mu \mathrm{g} / \mathrm{kg})$ and then re-challenged again after $15 \mathrm{~min}$ of recovery and a TLC breath with a higher dose $(371 \mu \mathrm{g} / \mathrm{kg})$ of $\mathrm{MCh}$, exhibited a smaller response after the high dose than lower doses (Figure 9B) even though MCh-response is well-known to be dosedependent. Despite variability, an increased number of ventilation defects and degree of bronchoconstriction were achieved with bolus injection of $\mathrm{MCh}$ compared to continuous infusion (Figure 10).

\subsection{Improved Reliability and Robustness of MCh Delivery}

During the course of these studies, it became evident that the degree of bradycardia induced by a standard dose of MCh is a critical indicator of MCh potency. The degree of bradycardia induced is directly related to the dose of MCh delivered(19). Thus, long-term tracings of bradycardia episodes in response to MCh challenge became essential to establishing reproducibility. Bradycardia was not reproducible under our initial protocol for MCh delivery, as shown in Figure 11A, where each of several $125 \mu \mathrm{g} / \mathrm{kg}$ bolus deliveries resulted in radically different amounts of bradycardia. The reproducibility of induced bradycardia is significantly improved, as shown in 11B, and $11 \mathrm{C}$ depicts heart rate changes after $\mathrm{MCh}$ challenge under the new protocol in a control and Ova/Ova mouse. With the improved MCh delivery procedures, the ${ }^{3} \mathrm{He}$ imaging studies showed that induced bronchoconstriction became much stronger, and ventilation defects became more numerous and both effects lasted longer. The increased bronchoconstriction of the medial lobe bronchus is illustrated in Figure 12, which compares images acquired using the initial $\mathrm{MCh}$ delivery protocol and the revised one. For a moderate MCh dose of $125 \mu \mathrm{g} / \mathrm{kg}$, the new delivery method achieved 65-100\% constriction where the initial methods achieved only $25-60 \%$ constriction.

In fact, many of the defects were sufficiently long-lasting to be detectable even in a naïve mouse on a 5.75-minute 3D imaging scan initiated 2 minutes after a $125 \mu \mathrm{g} / \mathrm{kg}$ bolus injection. The ability to detect ventilation defects on 3D images in control mice after MCh challenge had not been possible before(12), and clearly indicated that the new $\mathrm{MCh}$ procedure provides a far more potent challenge. Furthermore, this observation pointed to the value of including in our protocol a 3D scan immediately following the 2D dynamic image acquisition during $\mathrm{MCh}$ challenge. This 3D scan could then be used to evaluate the more persistent ventilation abnormalities with finer detail and thus complement the high-temporal resolution 2D timecourse study to provide the most comprehensive possible picture. The complete protocol we now use is presented in Figure 13, which with our current ${ }^{3} \mathrm{He}$ capacity of 1.2L, allows us to fully examine two mice per day.

The new protocol was used to acquire an image dataset in an Ova/Ova mouse and is shown in Figure 14. First, the high-resolution 3D image acquired prior to MCh challenge shows a lung entirely free of ventilation defects (Figure 14A). Then, a 2D time-course following a $250 \mu \mathrm{g} /$ $\mathrm{kg} \mathrm{MCh}$ dose shows dramatic bronchoconstriction, accompanied by complete cessation of ventilation in the caudal, medial, and accessory lobes (Figure 14C). Interestingly, as evident on the 2D time-course images, the caudal lobe defect resolves and subsequently ventilation is re-constituted during the 2 minute series of scans. The defects in the caudal and medial lobes persisted sufficiently long to be readily visualized in the 3D images (Figure 14B). However, 
the accessory lobe defect that had been evident on the 2D time-course was not visualized in the 3D image, since ventilation to this lobe was shown to be restored $96 \mathrm{~s}$ after MCh challenge during the time-course study.

Under the new protocol, only 1 dose of MCh ( 125 or $250 \mu \mathrm{g} / \mathrm{kg})$ is typically used rather than a complete dose-response study. This is a concession needed to conserve the limited supply of $\mathrm{HP}^{3} \mathrm{He}$ gas available per day. The 3D scans consume about $150 \mathrm{ml}$ each, and the $2 \mathrm{D}$ about $80 \mathrm{ml}$. Our current polarizer produces $\sim 1$ liter of gas per day, hence permitting 2 animals per day to be evaluated.

\section{Discussion}

\subsection{Ventilation Defects}

Our findings of whole lobar and fissure defects prior to $\mathrm{MCh}$ challenge were interesting and unexpected. Based on their frequent occurrence in this small study, these defects are presumably quite common in the Ova/Ova model of acute asthma. Given defects of this size, one would expect these animals to also exhibit increased airway resistance at baseline. However, this was not observed in our own flexiVent studies, nor has increased baseline resistance been commonly reported in the physiology literature. This discrepancy may be explained by the typical use of $\sim 3 \mathrm{~cm} \mathrm{H}_{2} \mathrm{O}$ positive end expiratory pressure (PEEP) in most physiology studies, whereas no PEEP was used in our MRI studies. The application of PEEP is likely effective in preventing the alveolar collapse(21) that we now visualize on MRI. It is interesting to note that these baseline defects were not eliminated by application of a TLC breath, which is always done prior to ${ }^{3} \mathrm{He}$ imaging. Correspondingly, it has been observed that TLC breaths given to asthmatic patients after MCh challenge do not restore their airway resistance to baseline values. This phenomenon has been attributed increased bronchial airway tone and airway stiffness(7,22-24), which may also be factors that contribute to the baseline defects we observe in mice. The presence of baseline whole lobar defects and the effects of PEEP in Ova/Ova mice are worthy of future study to uncover the underlying mechanisms for their origin and effective strategies for their elimination. Moreover, the finding of baseline ventilation defects in Ova/Ova mice points to the value of including high-resolution pre-MCh 3D imaging in the improved imaging protocol.

The greater number of ventilation defects at baseline and following MCh exposure in the cranial lobe left lung in the Ova/Ova mice may indicate that these lobes receive a more significant exposure to Ova aerosol. This is plausible because their feeding bronchi would the first airways encountered by the aerosol. The lobar pattern of involvement was somewhat different in the challenge of the Ova/PBS mice, though the left lung was highly involved.

\subsection{Methacholine Variability}

While we were able to see several new and previously unrecognized aspects of MCh response using ${ }^{3} \mathrm{He} \mathrm{MRI}$, the most confounding finding was the highly variable and unpredictable response to $\mathrm{MCh}$ with the initial delivery protocol. We note that highly dilute solutions of $\mathrm{MCh}$, such as those needed for small animal experiments, are even more susceptible to degradation at warm temperatures than the more concentrated solutions used clinically, which have also been shown to degrade $(6,25,26)$. Degradation of MCh solution is known to be driven by several factors including exposure to warm temperatures, $\mathrm{pH}$, diluents, and sensitivity to light $(25$, 26). Hence, it is reasonable to conjecture that there is some aspect of the MRI experimental set-up that causes accelerated degradation of MCh solution, even beyond what has been previously reported. Specifically, the MRI set-up and experiment require considerably more time than bench-top physiology studies, and MCh must be delivered over a considerable distance. Ultimately, the observation that individual animals responded differently to serial 
challenges with the same MCh solution led us to conclude that the primary cause of variability was degradation of $\mathrm{MCh}$ in portions of the catheter inlet tubing.

Although, we have yet to uncover the underlying mechanism of the MCh degradation we have postulated, it is clear that the revised protocol for MCh delivery that assumes such degradation to take place, and takes steps to mitigate it, has generated dramatically improved reproducibility and magnitude of $\mathrm{MCh}$ response. Thus, frequent serial challenges with MCh (at least every 10-15 minutes) and occasional extension tube line flushes are critical to ensuring a consistent animal response to MCh injections. Specifically, a $40 \mu \mathrm{l}(\sim 125 \mu \mathrm{g} / \mathrm{kg})$ test bolus is applied and bradycardia is measured to ensure robust MCh response. Only once reproducibility is established in this way should the ${ }^{3} \mathrm{He}$ imaging study be initiated.

\subsection{Bolus versus Infusion Delivery of $\mathrm{MCh}$}

Our efforts to compare continuous infusion versus bolus injection of MCh were complicated by the variability of MCh delivery, but a few conclusions can be drawn. In all imaging studies using continuous infusion, the degree of bronchoconstriction and number of ventilation defects were consistently less than for similar doses delivered as a bolus. Moreover, ventilation defects recovered more quickly following infusion than after bolus injection. Finally, the same bolus/ infusion comparison made using the flexiVent, which was not complicated by the MCh delivery problem, also clearly resulted in an attenuated response to $\mathrm{MCh}$ infusion compared to bolus delivery. Thus, while the question of using MCh infusion to prolong ventilation defects during long-lasting 3D imaging remains one of interest, our tentative conclusion is that there are no striking advantages to infusion delivery.

\subsection{Bronchoconstriction with Improved Protocol}

As seen in Figure 12, the new method of MCh delivery causes large, consistent bronchoconstrictive responses in naïve, Ova/PBS, and Ova/Ova mice. Bronchoconstriction of the large airways immediately following MCh challenge is expected to be similar in Ova/Ova and control mice as the major airways have acetylcholine receptors that respond to the $\mathrm{MCh}$. Our chosen MCh concentration of $125 \mu \mathrm{g} / \mathrm{kg}$ is likely sufficient to saturate the receptors in both groups of animals, therefore causing similar bronchoconstriction of large airways. Hence, large airway bronchoconstriction observed in the 2D temporal dynamics series is a good indicator of MCh potency, but does not differentiate the Ova/Ova and Ova/PBS groups. However, the smaller airways do not contain smooth muscle, thus they also do not contain acetylcholine receptors. In these airways, one expects a more significant hyperresponsiveness in the Ova/Ova model caused by wall thickening and other effects of allergic inflammation. This hyperresponsiveness would manifest itself through decreased peripheral ventilation. This could explain why a greater number of ventilation defects are seen in Ova/Ova compared to controls despite similar degrees of larger airway bronchoconstriction. Hence, persistent ventilation defects may be a better way to differentiate hyperresponsiveness than large-airway bronchoconstriction.

In the example dynamic images of Figure 14, we noticed unexpected periods where the caudal lobe bronchus alternated between patency and complete bronchoconstriction. A possible explanation for this phenomenon may be due to an interplay between hyperresponsiveness of the caudal lobe bronchus and distal airways with subsequent bronchoconstriction, and the increased pressure formed in the proximal bronchus due to constant volume ventilation, thus causing it to open. NUMBERS MAKE MORE SENSE WHEN YOU HAVE MORE THAN 2 ITEMS

Another report from the literature has also demonstrated hypoventilation in distal airways of mouse models investigated with 3D imaging techniques(27). This study showed in both control 
mice with normal degrees of airway smooth muscle shortening and sensitized mice with excessive narrowing of the airway (thickened airway walls, hyperemia of tissues), that some airways distal to major conducting airway branches proceeded to full closure. Such distal airway closure has been attributed to airway wall thickening and an increased tendency of the airways to close due to excess mucus production or increased surface tension(28). This hypothesis fits well with the results of this study, as we are likely dynamically demonstrating the closure of these distal airways. The short-term dynamic changes in regional ventilation and bronchoconstriction demonstrated in the current study highlights the utility of 2D time-course images in the improved protocol.

\title{
5. Conclusions
}

The present study is a novel approach to visualize MCh response in treatment and control groups of an animal model of allergic inflammation using HP ${ }^{3} \mathrm{He}$ MRI. Specifically, we discovered baseline ventilation defects, including whole lobar and fissure defects that were present in Ova/Ova animals, but not Ova/PBS animals. Following MCh exposure, ${ }^{3} \mathrm{He}$ MRI depicted both bronchoconstriction and development of ventilation defects. The most numerous ventilation defects were noted in the cranial lobe and left lung, likely due to the branching pattern of murine airways.

However, this study also exposed specific difficulties associated with i.v. MCh delivery in the small animal MRI environment. We have developed simple methods to eliminate the variability in MCh response and now successfully demonstrate that i.v. MCh challenge reproducibly leads to profound bronchoconstriction and ventilation defects that can be present for several minutes post-challenge. By solving the MCh-delivery problem in the small animal MRI environment, we have been able to develop a protocol that combines high-resolution 3D imaging and 2D time-course studies to comprehensively phenotype MCh sensitivity in the adult mouse lung. Such promising attributes of the improved protocol should enable reliable MCh delivery and make ${ }^{3} \mathrm{He}$ MRI phenotyping a valuable tool for investigating novel hypotheses of regional dysfunction in asthmatic airway disease, and for developing meaningful approaches that optimize site-specific therapeutic interventions.

\section{Acknowledgements}

We thank Dr. G. Allan Johnson for encouraging us to write this manuscript and Merck Frosst \& Co. for providing the expertise necessary to plan these experiments, and the funding to carry them out. Imaging and data analysis were performed at the Duke Center for In Vivo Microscopy, an NCRR National Biomedical Technology Resource Center, and ovalbumin exposure and airway physiology measurements were conducted in Dr. Michael Foster's laboratory (Pulmonary Medicine, Duke University Medical Center, Durham, NC, USA).

\author{
Sponsors: \\ Contract/grant sponsor: Merck \& Co, Inc. \\ Contract/grant sponsor: National Institutes of Health (NIH)
}

contract/grant numbers: 5R21HL87094-2, ES 11961, and ES 16347. may want to indicate agencies, like Bas' grant is from NHLBI, and I do not know where the ES grants originate>

Contract/grant sponsor: NIH/National Center for Research Resources (NCRR)

contract/grant number: P41 RR005959.

\section{Abbreviations used}

AHR, airways hyperreactivity

BAL, bronchoalveolar lavage 
ECG, electrocardiogram

$\mathrm{HR}$, heart rate

HP, hyperpolarized

i.p, intraperitoneal

i.v, intravenous

MCh, methacholine

Ova, ovalbumin

Ova/Ova, Ova sensitization/Ova challenge

Ova/PBS, Ova sensitization/PBS challenge

PBS, phosphate buffered saline

PEEP, positive end expiratory pressure

PIP, peak inspiratory pressure

PBS, phosphate buffered saline

TLC, total lung capacity

\section{References}

1. Fain SB, Korosec FR, Holmes JH, O'Halloran R, Sorkness RL, Grist TM. Functional lung imaging using hyperpolarized gas MRI. J Magn Reson Imaging 2007;25:910-923. [PubMed: 17410561]

2. Walker TG, Happer W. Spin-exchange optical pumping of noble-gas nuclei. Reviews of Modern Physics 1997;69:629-642.

3. de Lange EE, Altes TA, Patrie JT, Gaare JD, Knake JJ, Mugler JP III, Platts-Mills TA. Evaluation of Asthma With Hyperpolarized Helium-3 MRI: Correlation With Clinical Severity and Spirometry. Chest 2006;130:1055-1062. [PubMed: 17035438]

4. Altes TA, Powers PL, Knight-Scott J, Rakes G, Platts-Mills TA, de Lange EE, Alford BA, Mugler JP 3rd, Brookeman JR. Hyperpolarized 3He MR lung ventilation imaging in asthmatics: preliminary findings. J Magn Reson Imaging 2001;13:378-384. [PubMed: 11241810]

5. Samee S, Altes T, Powers P, de Lange EE, Knight-Scott J, Rakes G, Mugler JP, Ciambotti JM, Alford BA, Brookeman JR, Platts-Mills TA. Imaging the lungs in asthmatic patients by using hyperpolarized helium-3 magnetic resonance: assessment of response to methacholine and exercise challenge. $\mathrm{J}$ Allergy Clin Immunol 2003;111:1205-1211. [PubMed: 12789218]

6. Crapo RO, Casaburi R, Coates AL, Enright PL, Hankinson JL, Irvin CG, MacIntyre NR, McKay RT, Wanger JS, Anderson SD, Cockcroft DW, Fish JE, Sterk PJ. Guidelines for methacholine and exercise challenge testing-1999. This official statement of the American Thoracic Society was adopted by the ATS Board of Directors, July 1999. Am J Respir Crit Care Med 2000;161:309-329. [PubMed: 10619836]

7. Kips JC, Anderson GP, Fredberg JJ, Herz U, Inman MD, Jordana M, Kemeny DM, Lötvall J, Pauwels RA, Plopper CG, Schmidt D, Sterk PJ, Van Oosterhout AJM, Vargaftig BB, Chung KF. Murine models of asthma. The European respiratory journal 2003;22:374-382. [PubMed: 12952276]

8. Glaab T, Taube C, Braun A, Mitzner W. Invasive and noninvasive methods for studying pulmonary function in mice. Respir Res 2007;8:63. [PubMed: 17868442]

9. Bates JH, Irvin CG. Measuring lung function in mice: the phenotyping uncertainty principle. J Appl Physiol 2003;94:1297-1306. [PubMed: 12626466]

10. Irvin CG, Bates JH. Measuring the lung function in the mouse: the challenge of size. Respir Res 2003;4:4. [PubMed: 12783622]

11. Winkler T, Venegas JG. Complex airway behavior and paradoxical responses to bronchoprovocation. J Appl Physiol 2007;103:655-663. [PubMed: 17478609]

12. Driehuys B, Walker J, Pollaro J, Cofer GP, Mistry N, Schwartz D, Johnson GA. 3He MRI in mouse models of asthma. Magn Reson Med 2007;58:893-900. [PubMed: 17969115]

13. Therien AG, Bernier V, Weicker S, Tawa P, Falgueyret JP, Mathieu MC, Honsberger J, Pomerleau V, Robichaud A, Stocco R, Dufresne L, Houshyar H, Lafleur J, Ramachandran C, O'Neill GP, Slipetz D, Tan CM. Adenovirus IL-13-induced Airway Disease in Mice: A Corticosteroid-resistant Model of Severe Asthma. Am J Respir Cell Mol Biol. 2008[Epub ahead of print]. 
14. Whitehead GS, Walker JK, Berman KG, Foster WM, Schwartz DA. Allergen-induced airway disease is mouse strain dependent. Am J Physiol Lung Cell Mol Physiol 2003;285:L32-L42. [PubMed: 12626335]

15. Chen BT, Brau AC, Johnson GA. Measurement of regional lung function in rats using hyperpolarized 3helium dynamic MRI. Magn Reson Med 2003;49:78-88. [PubMed: 12509822]

16. Chen BT, Yordanov AT, Johnson GA. Ventilation-synchronous magnetic resonance microscopy of pulmonary structure and ventilation in mice. Magn Reson Med 2005;53:69-75. [PubMed: 15690504]

17. Deninger AJ, Mansson S, Petersson JS, Pettersson G, Magnusson P, Svensson J, Fridlund B, Hansson G, Erjefeldt I, Wollmer P, Golman K. Quantitative measurement of regional lung ventilation using 3He MRI. Magn Reson Med 2002;48:223-232. [PubMed: 12210930]

18. Song J, Liu QH. An efficient MR image reconstruction method for arbitrary K-space trajectories without density compensation. Conf Proc IEEE Eng Med Biol Soc 2006;1:3767-3770. [PubMed: 17946203]

19. Walker JK, Peppel K, Lefkowitz RJ, Caron MG, Fisher JT. Altered airway and cardiac responses in mice lacking G protein-coupled receptor kinase 3. Am J Physiol 1999;276:R1214-R1221. [PubMed: 10198406]

20. Gleich GJ. The eosinophil and bronchial asthma: current understanding. J Allergy Clin Immunol 1990;85:422-436. [PubMed: 2406322]

21. Halter JM, Steinberg JM, Schiller HJ, DaSilva M, Gatto LA, Landas S, Nieman GF. Positive endexpiratory pressure after a recruitment maneuver prevents both alveolar collapse and recruitment/ derecruitment. Am J Respir Crit Care Med 2003;167:1620-1626. [PubMed: 12615628]

22. An SS, Bai TR, Bates JH, Black JL, Brown RH, Brusasco V, Chitano P, Deng L, Dowell M, Eidelman DH, Fabry B, Fairbank NJ, Ford LE, Fredberg JJ, Gerthoffer WT, Gilbert SH, Gosens R, Gunst SJ, Halayko AJ, Ingram RH, Irvin CG, James AL, Janssen LJ, King GG, Knight DA, Lauzon AM, Lakser OJ, Ludwig MS, Lutchen KR, Maksym GN, Martin JG, Mauad T, McParland BE, Mijailovich SM, Mitchell HW, Mitchell RW, Mitzner W, Murphy TM, Pare PD, Pellegrino R, Sanderson MJ,

Schellenberg RR, Seow CY, Silveira PS, Smith PG, Solway J, Stephens NL, Sterk PJ, Stewart AG, Tang DD, Tepper RS, Tran T, Wang L. Airway smooth muscle dynamics: a common pathway of airway obstruction in asthma. Eur Respir J 2007;29:834-860. [PubMed: 17470619]

23. Jackson AC, Murphy MM, Rassulo J, Celli BR, Ingram RH Jr. Deep breath reversal and exponential return of methacholine-induced obstruction in asthmatic and nonasthmatic subjects. J Appl Physiol 2004;96:137-142. [PubMed: 14660493]

24. Mitchell HW, Turner DJ, Gray PR, McFawn PK. Compliance and stability of the bronchial wall in a model of allergen-induced lung inflammation. J Appl Physiol 1999;86:932-937. [PubMed: 10066707]

25. Acar V, Houri JJ, Le Hoang MD, Pradeau D, Guyon F. Stability of stored methacholine solutions: study of hydrolysis kinetic by IP-LC. J Pharm Biomed Anal 2001;25:861-869. [PubMed: 11377069]

26. Watson BL, Cormier RA, Harbeck RJ. Effect of $\mathrm{pH}$ on the stability of methacholine chloride in solution. Respir Med 1998;92:588-592. [PubMed: 9692128]

27. Lundblad LKA, Thompson-Figueroa J, Allen GB, Rinaldi L, Norton RJ, Irvin CG, Bates JHT. Airway Hyperresponsiveness in Allergically Inflamed Mice: The Role of Airway Closure. Am J Respir Crit Care Med 2007;175:768-774. [PubMed: 17255559]

28. Agrawal A. Mucous obstruction and airway hyperresponsiveness in mice. Am J Respir Crit Care Med 2008;177:1171. [PubMed: 18460463] author reply 1171-2. 


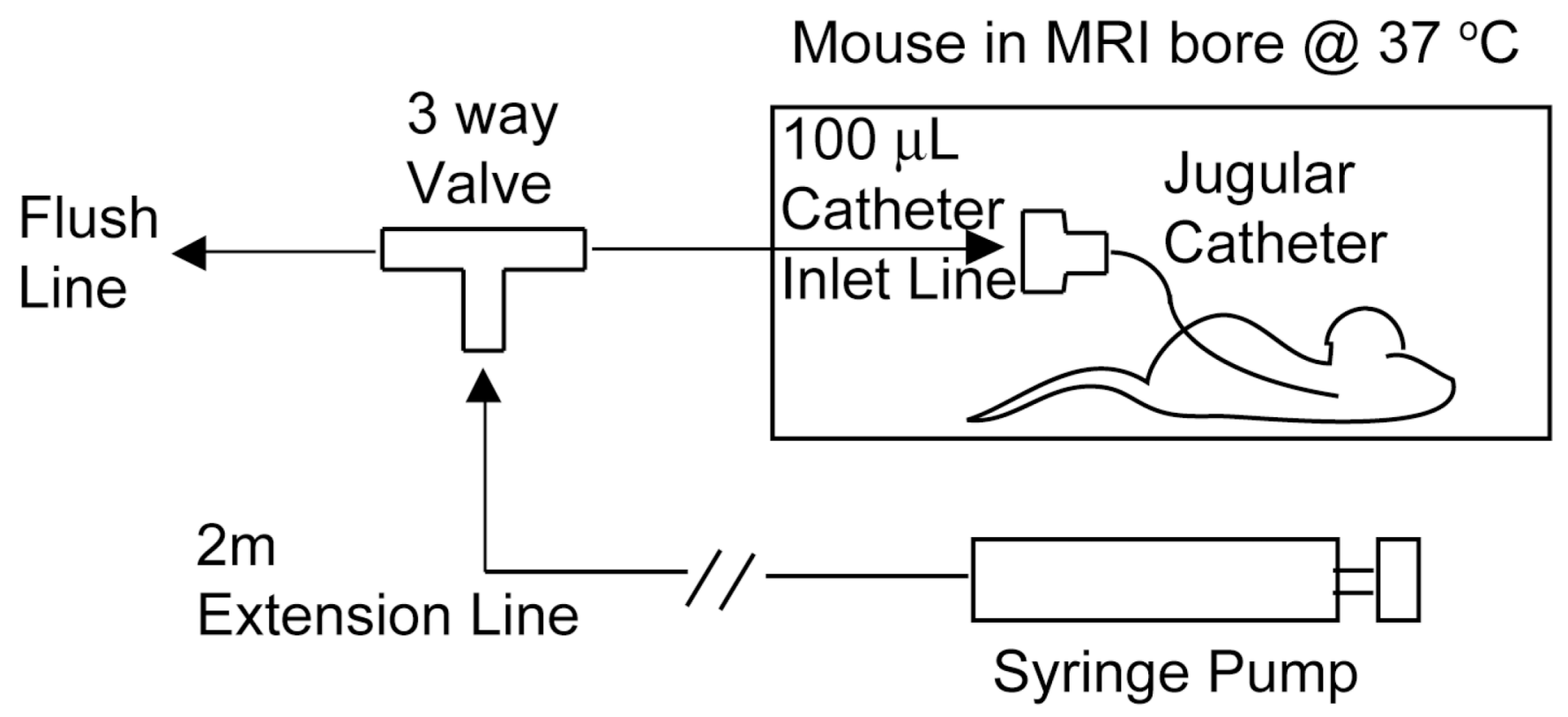

Figure 1.

Improved MCh Delivery Setup. A three-way "T" valve allows flushing of potentially degraded MCh solution in the lines leading to the jugular catheter. After such a flush, an extra bolus was delivered to clear the catheter inlet line whose volume was made as small as possible $(<200$ $\mu \mathrm{L}$ ) to limit the amount of degraded MCh that was delivered to the mouse during clearance. $\mathrm{MCh}$ is hypothesized to degrade primarily in the catheter inlet, within the bore of the magnet. 


\section{TOP}

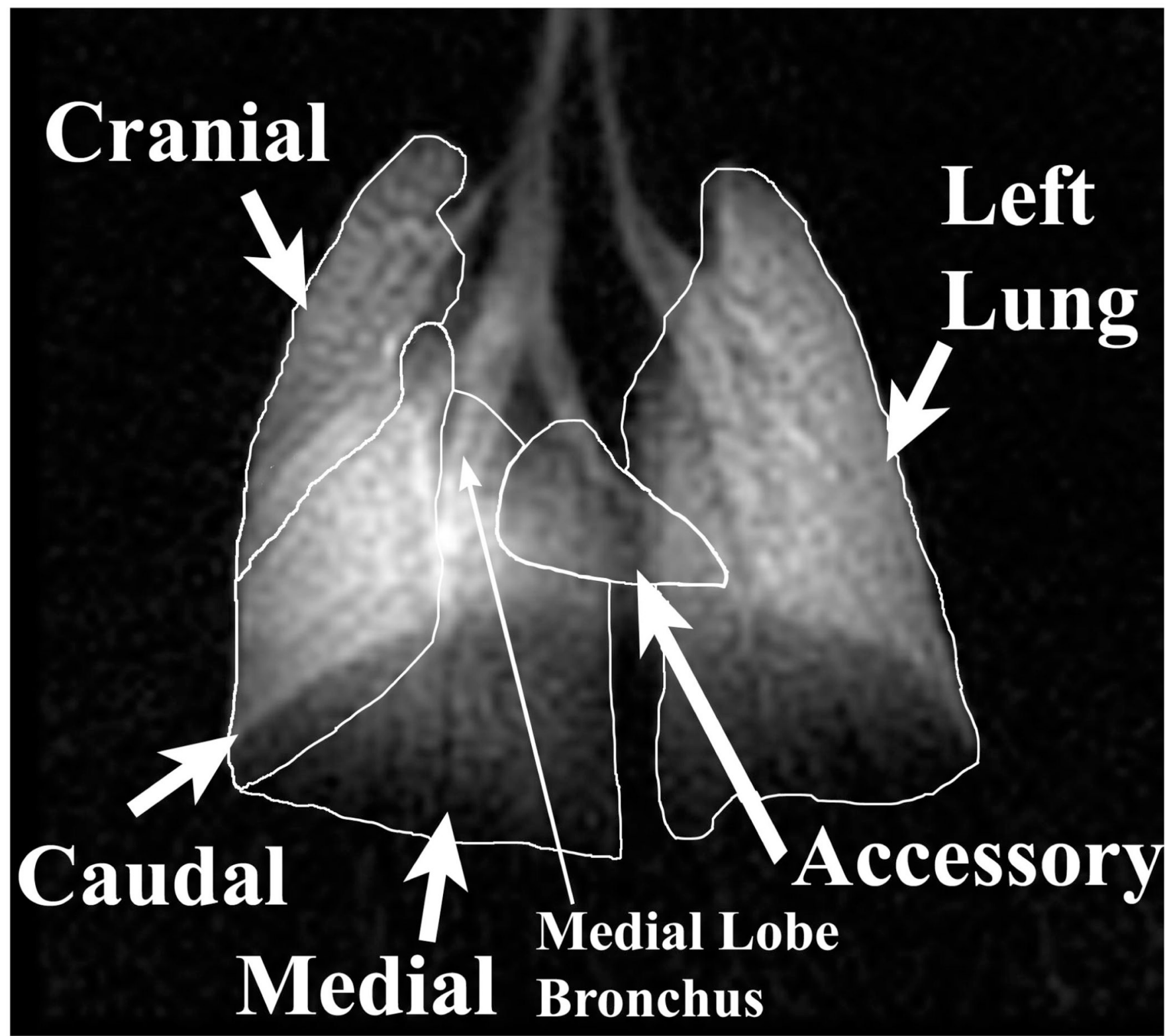

Figure 2.

In vivo lung map based on a $2 \mathrm{D}$ image detailing the location of the left lung and the four right lung lobes: cranial, medial, caudal, and accessory. Lobe location was determined through known mouse lung anatomy, airway branching patterns, and correlation of 2D images with 3D datasets, where lobes are distinguished through easily identifiable fissures. The medial lobe bronchus (small arrow) was used to measure bronchoconstriction[AT17]. 

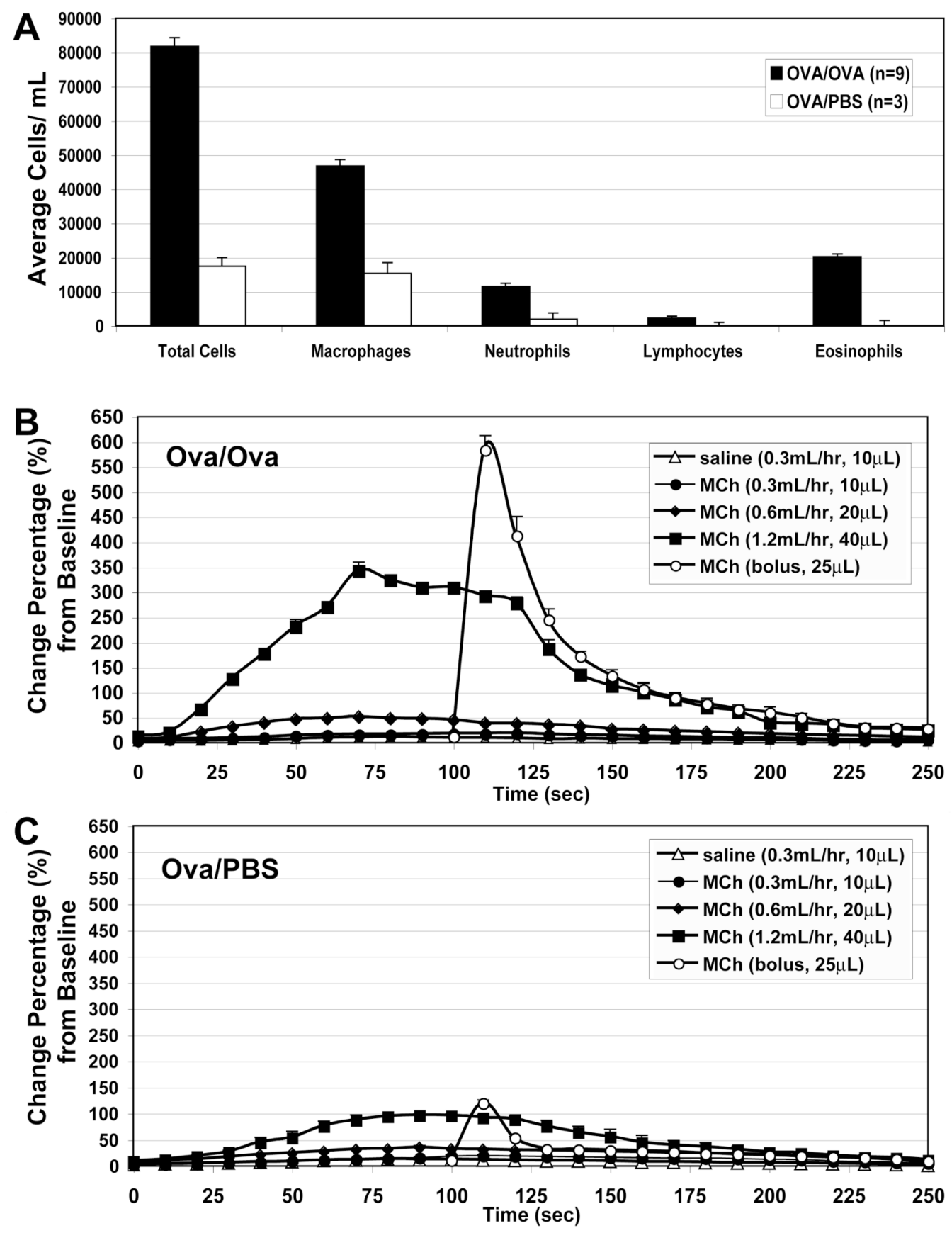

Figure 3.

BAL cell counts and flexiVent resistance measures of Ova/Ova versus Ova/PBS mice. (A) BAL Differential cell counts were increased in Ova/Ova vs. Ova/PBS mice, with prominent increases in macrophages, neutrophils, and eosinophils. (B) Airway resistance measurements in Ova/Ova mice using i.v. infusion of normal saline or MCh and bolus injection. Error bars indicate standard error of the mean $(\mathrm{N}=3)$. (C) Airway resistance measurements in Ova/PBS under similar conditions $(\mathrm{N}=3)$. 

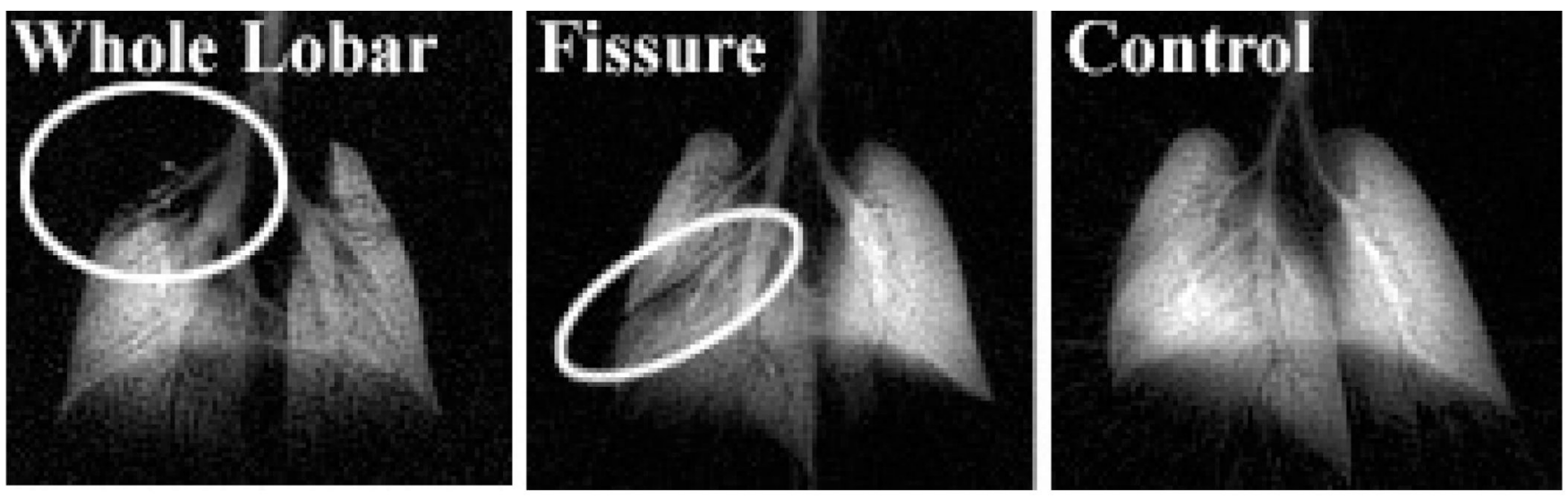

Figure 4.

Examples of pre-MCh defects. The left pane displays a whole missing cranial lobe at baseline in an Ova/Ova mouse (circled). The middle panel shows an Ova/Ova mouse with a fissure defect at baseline. The right panel is a baseline image of an Ova/PBS control mouse with no evident ventilation defects. 


\section{TOP}
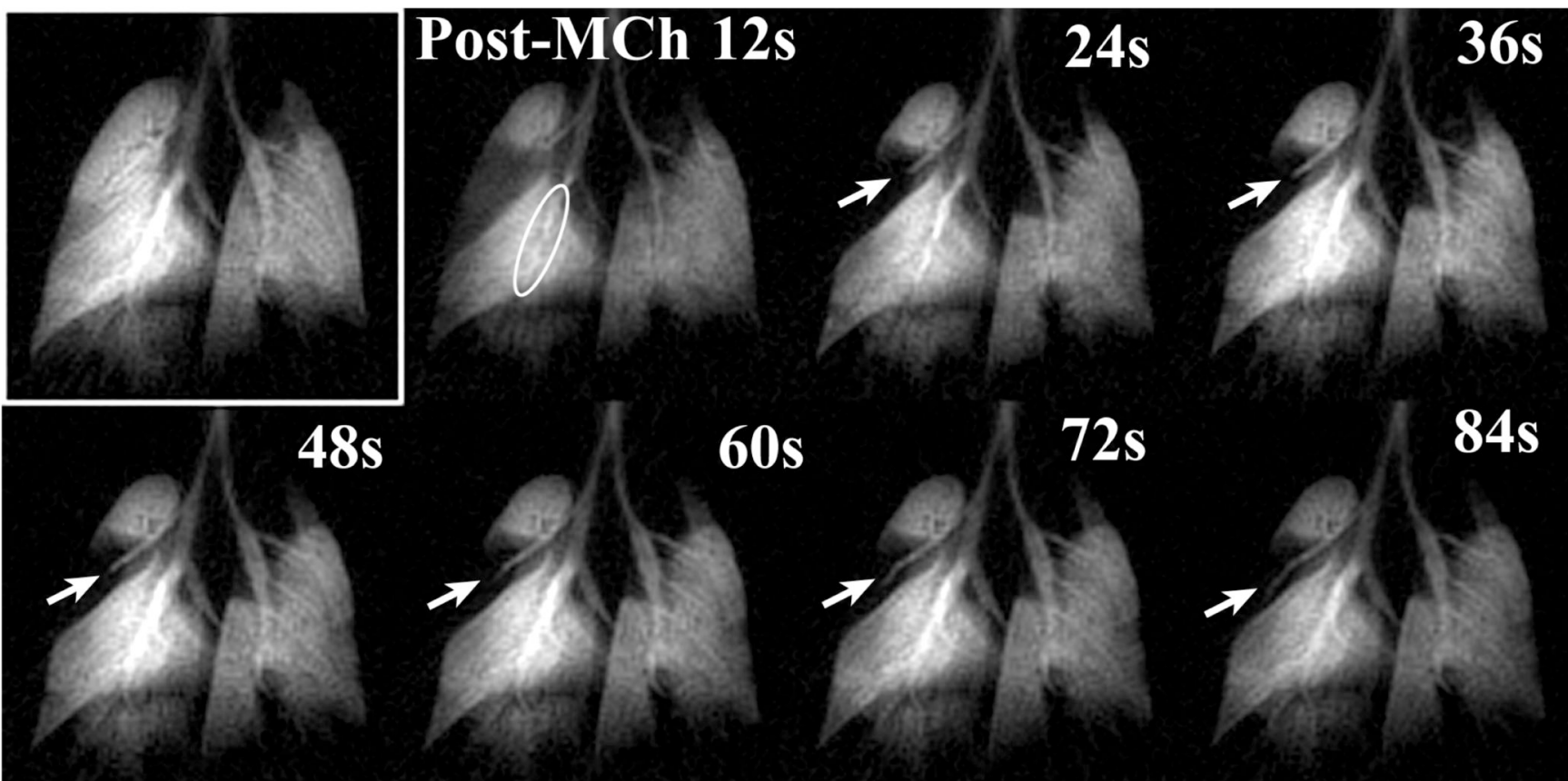

84s

Figure 5.

2D time-course images of an Ova/Ova mouse before and after exposure to a $250 \mu \mathrm{g} / \mathrm{kg}$ bolus injection of MCh using the initial protocol. The time-course displays bronchoconstriction in all visible airways evident for the first $24 \mathrm{~s}$, followed by relaxation to baseline bronchial diameters. The bronchoconstriction of the medial lobe is circled in the $12 \mathrm{~s}$ post-MCh timepoint. The series also shows the evolution of a large cranial lobe defect that did not return to baseline values by the end of the imaging (noted by arrows[AT19]). 


\section{TOP}
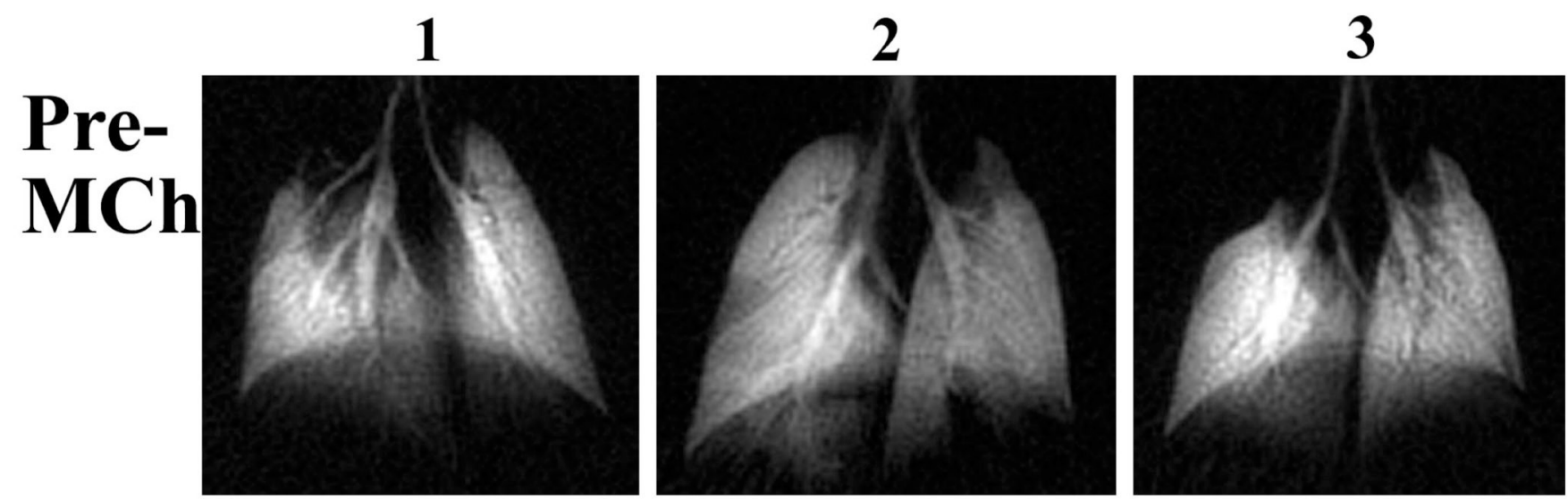

Post-Accessory

$\mathrm{MCh}$
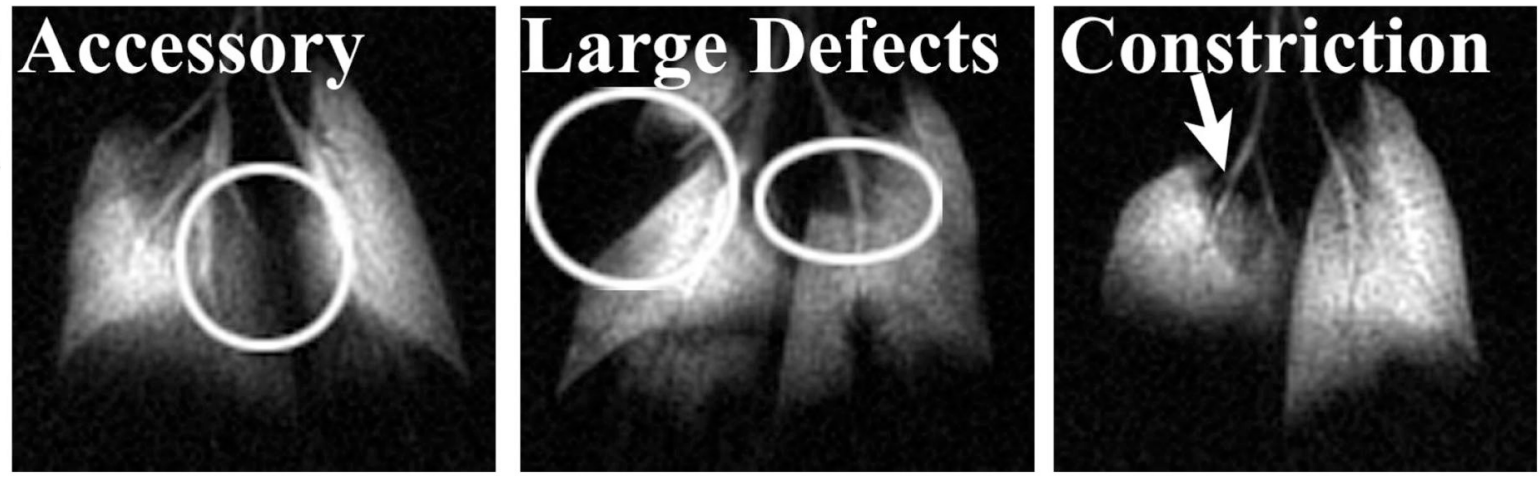

Figure 6.

Pre-(top row) and post- MCh (bottom row) ventilation defects for three separate Ova/Ova animals imaged under the initial protocol. The first animal received a continuous infusion of $\mathrm{MCh}$ at $3.6 \mathrm{~mL} / \mathrm{hr}(560 \mu \mathrm{g} / \mathrm{kg})$, resulting in complete occlusion of distal end of the major bronchus to the accessory lobe and an associated loss of ventilation (circle). The second animal received a $250 \mu \mathrm{g} / \mathrm{kg}$ MCh bolus injection, creating prominent ventilation defects in the cranial lobe of the right lung and the left lung (circles). The third animal exhibited a whole lobar cranial defect at baseline and after receiving a $320 \mu \mathrm{g} / \mathrm{kg}$ MCh bolus, experienced constriction of most major airways including the right main stem bronchus (arrow). 


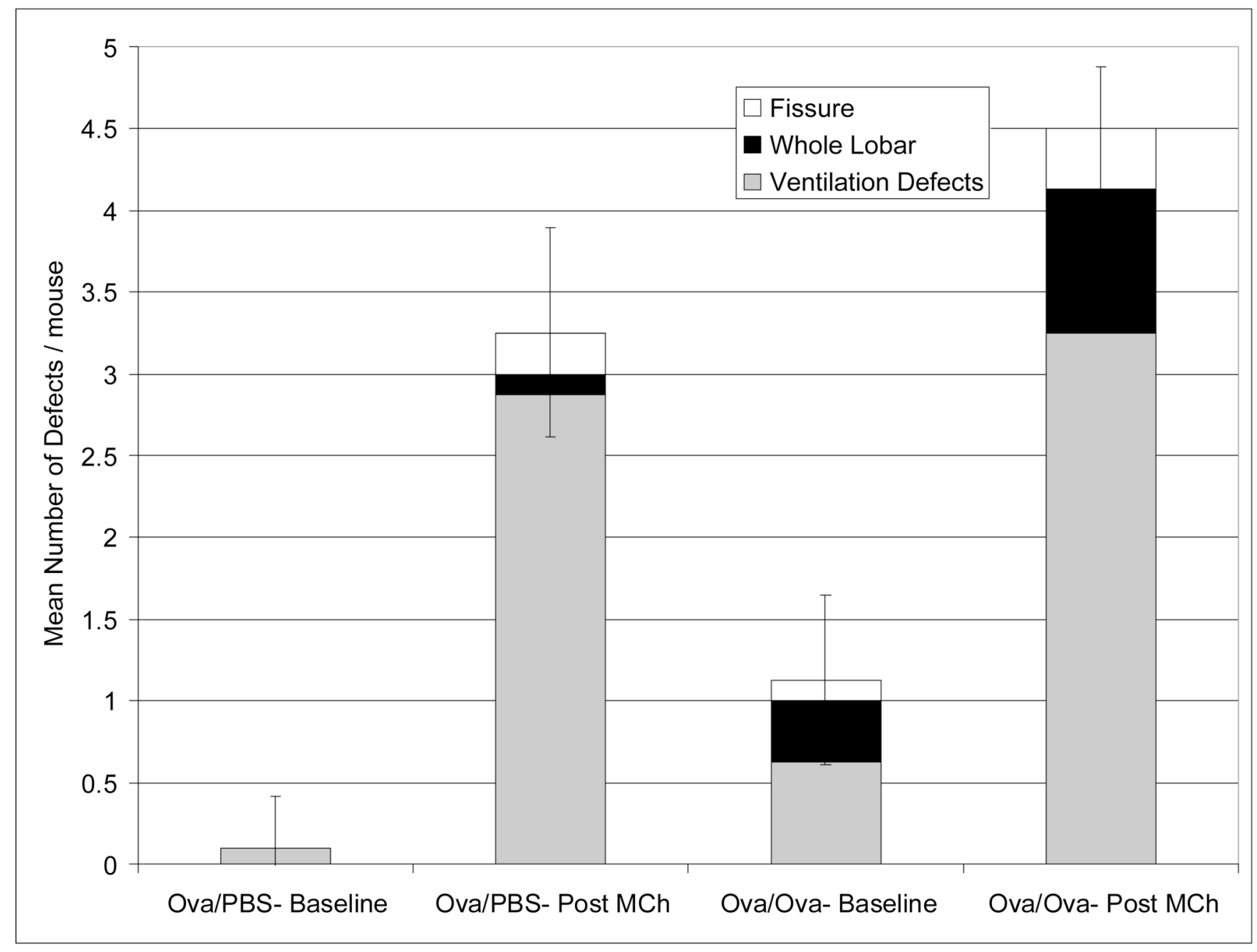

Figure 7.

Mean number of defects per mouse in Ova/PBS and Ova/Ova mice observed pre- and postMCh under the initial protocol. The white shaded areas represent fissure defects, the black shaded areas represent whole lobar defects, and gray areas represent the remaining defects. Ova/Ova mice exhibited considerably more pre-MCh defects, including some that consumed an entire lobe (whole lobar). Such whole lobar defects were not seen pre-MCh in the control mice. Both groups exhibited an equivalent number of fissure defects post-MCh. Error bars indicate standard deviation of the mean for each group $(\mathrm{N}=8)$. 


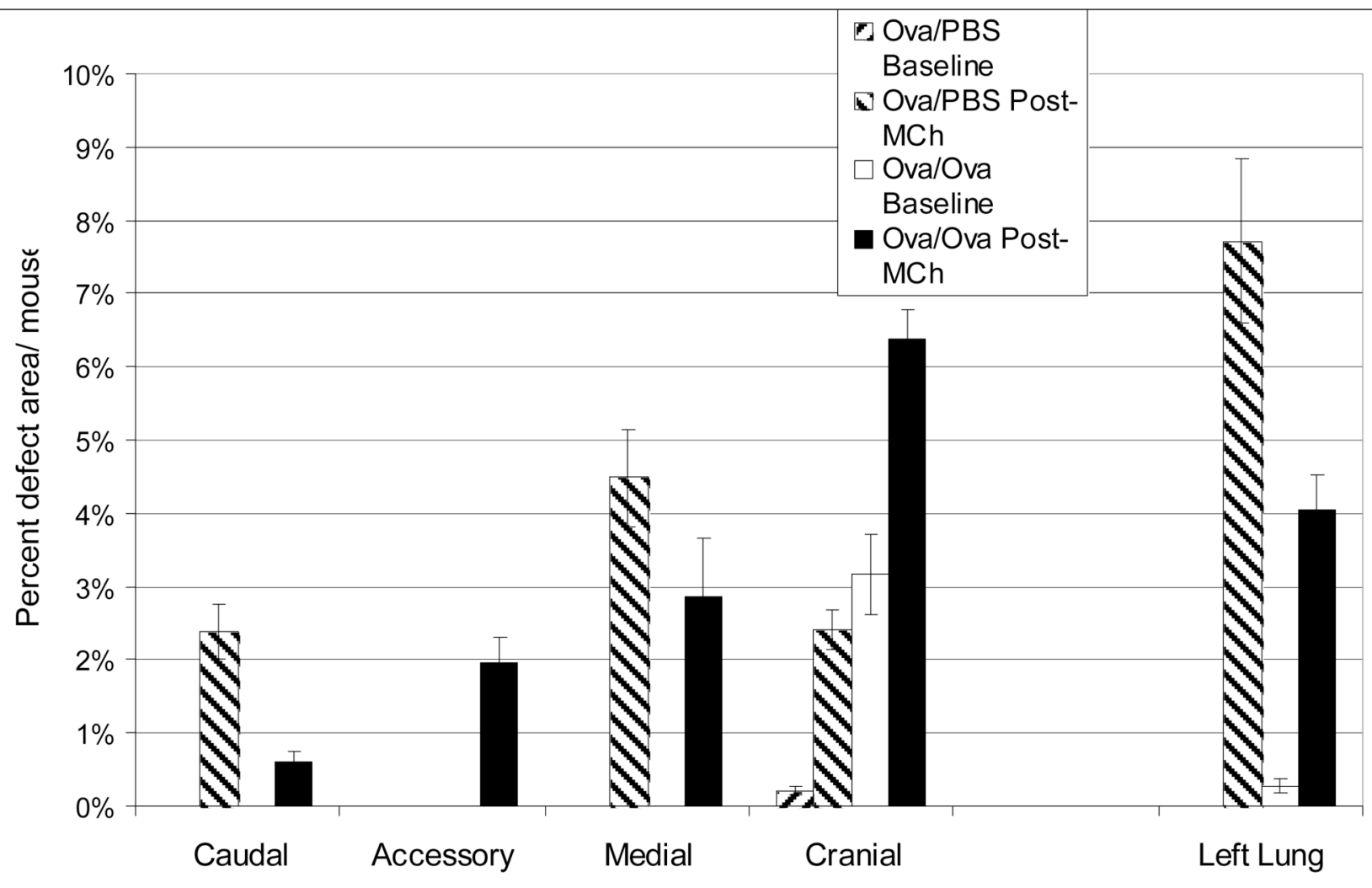

Figure 8.

Mean areas of ventilation defects analyzed by lobe under the initial protocol. In Ova/Ova mice all the pre-MCh ventilation defects arise in the left and cranial lobes and these lobes also have the most post-MCh ventilation loss. This is likely because the bronchi supplying these lobes are the first airway branches and suggests that the Ova aerosol reaches these lobes with greater efficiency. The control group showed virtually no pre-MCh defects and exhibited a majority of post-MCh defects in the left and medial lobes. Error bars indicate standard deviation of the mean for each group, grouped by lobe. 


\section{TOP}

\section{Ova/PBS- $250 \mu \mathrm{g}$ Ova/Ova- $640 \mu \mathrm{g}$}
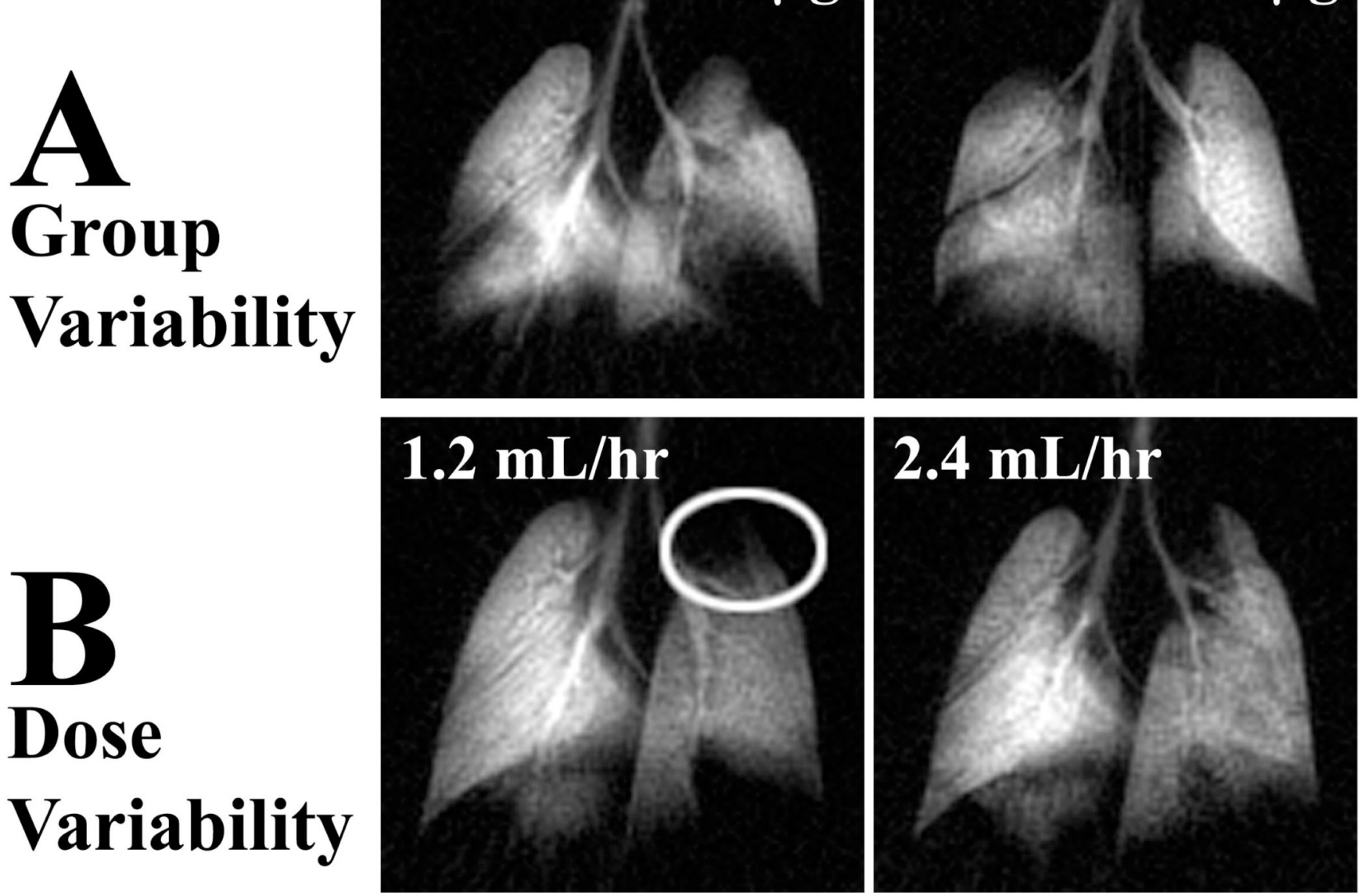

Figure 9.

Variability of MCh delivery under the initial protocol. (A) Ova/PBS control after a $250 \mu \mathrm{g} / \mathrm{kg}$ bolus displays a greater number and size of ventilation defects than an Ova/Ova mouse following a $640 \mu \mathrm{g} / \mathrm{kg}$ bolus. (B) An individual Ova/Ova animal was challenged with a continuous infusion of $\mathrm{MCh}$ at $1.2 \mathrm{~mL} / \mathrm{hr}(186 \mu \mathrm{g} / \mathrm{kg})$ and $2.4 \mathrm{~mL} / \mathrm{hr}(371 \mu \mathrm{g} / \mathrm{kg})$. At the low dose it exhibited a large ventilation defect in the apical portion of the left lung, which was not visible at the higher dose, although it did cause more bronchoconstriction. 

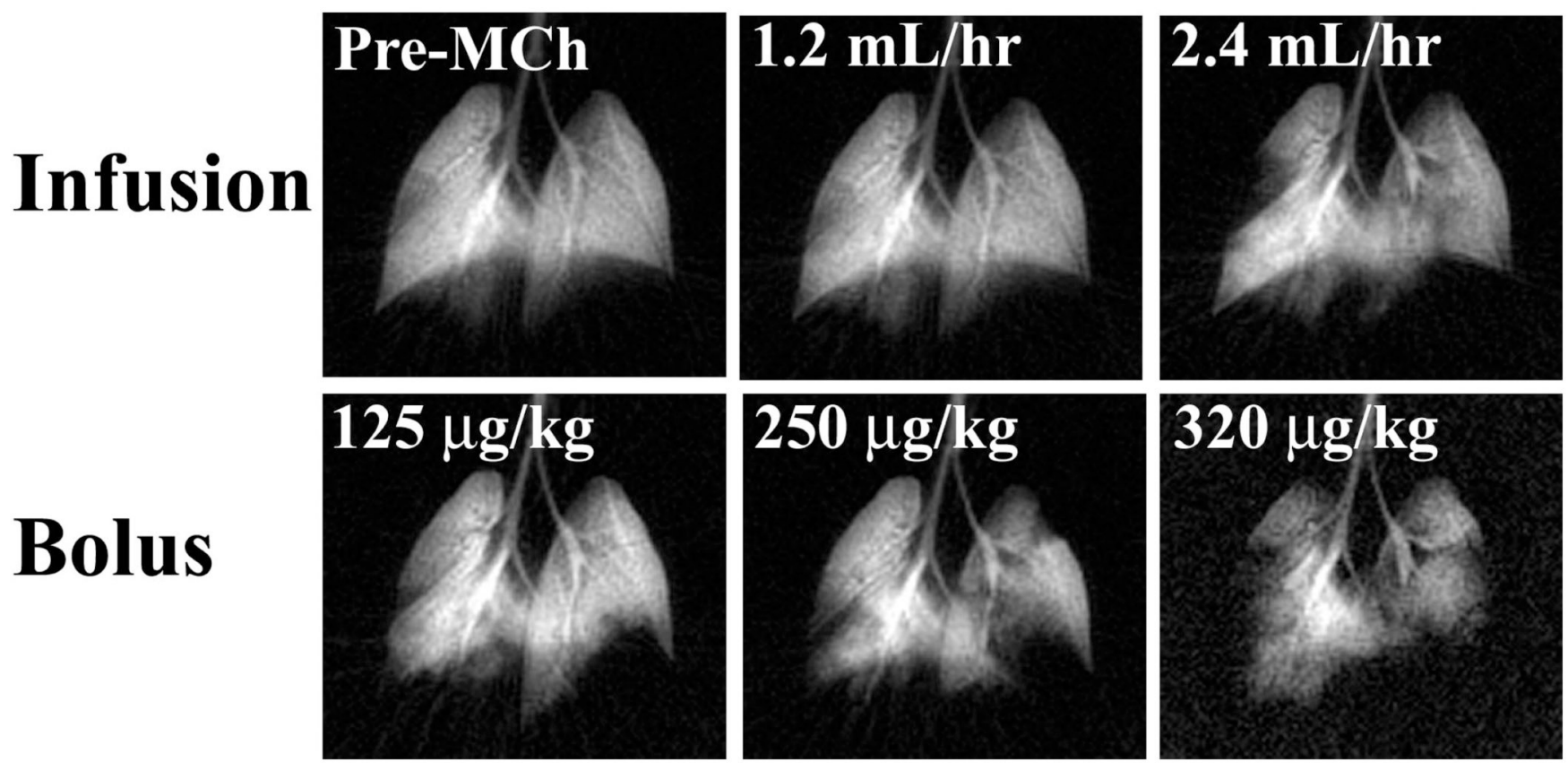

Figure 10.

Comparison of continuous infusion vs. bolus injection of $\mathrm{MCh}$ using the initial protocol. All images were obtained from the same Ova/Ova mouse. Images obtained after infusion (top row) of MCh at $1.2 \mathrm{~mL} / \mathrm{hr}(186 \mu \mathrm{g} / \mathrm{kg})$ and $2.4 \mathrm{~mL} / \mathrm{hr}(371 \mu \mathrm{g} / \mathrm{kg})$ showed fewer and smaller defects than images following MCh bolus injection (bottom row) of 125, 250, and $320 \mu \mathrm{g} / \mathrm{kg}$, respectively. 

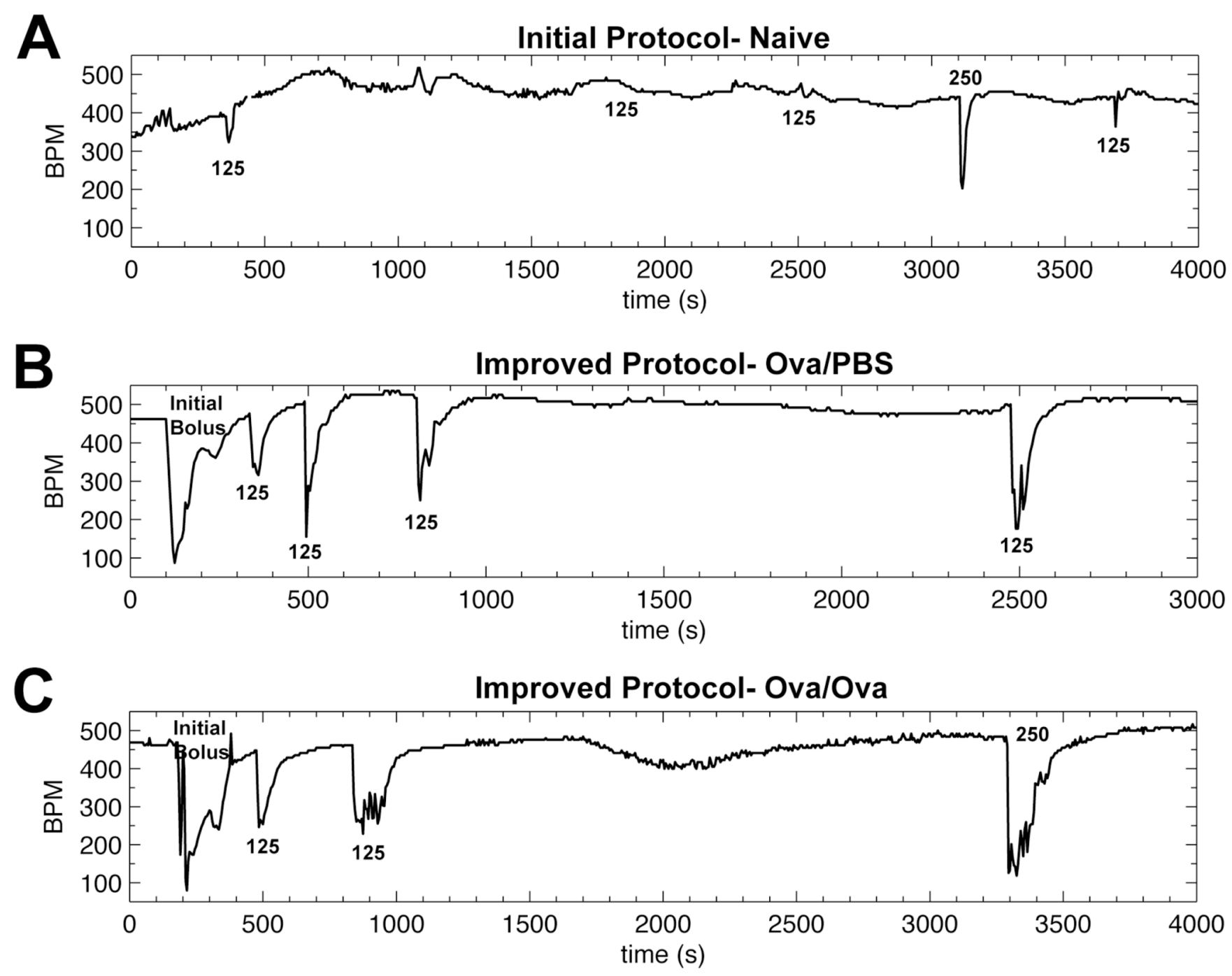

Figure 11.

Recordings of heart rate following MCh Challenge. (A) Naïve mouse showing a high-degree of variability in $\mathrm{HR}$ response after $\mathrm{MCh}$ injection under the initial protocol. (B) Control mouse with MCh injections via the improved protocol showing much stronger and more consistent MCh response. (C) Ova/Ova mouse also showing strong, consistent, and dose-dependent $\mathrm{MCh}$ response under the improved protocol. 


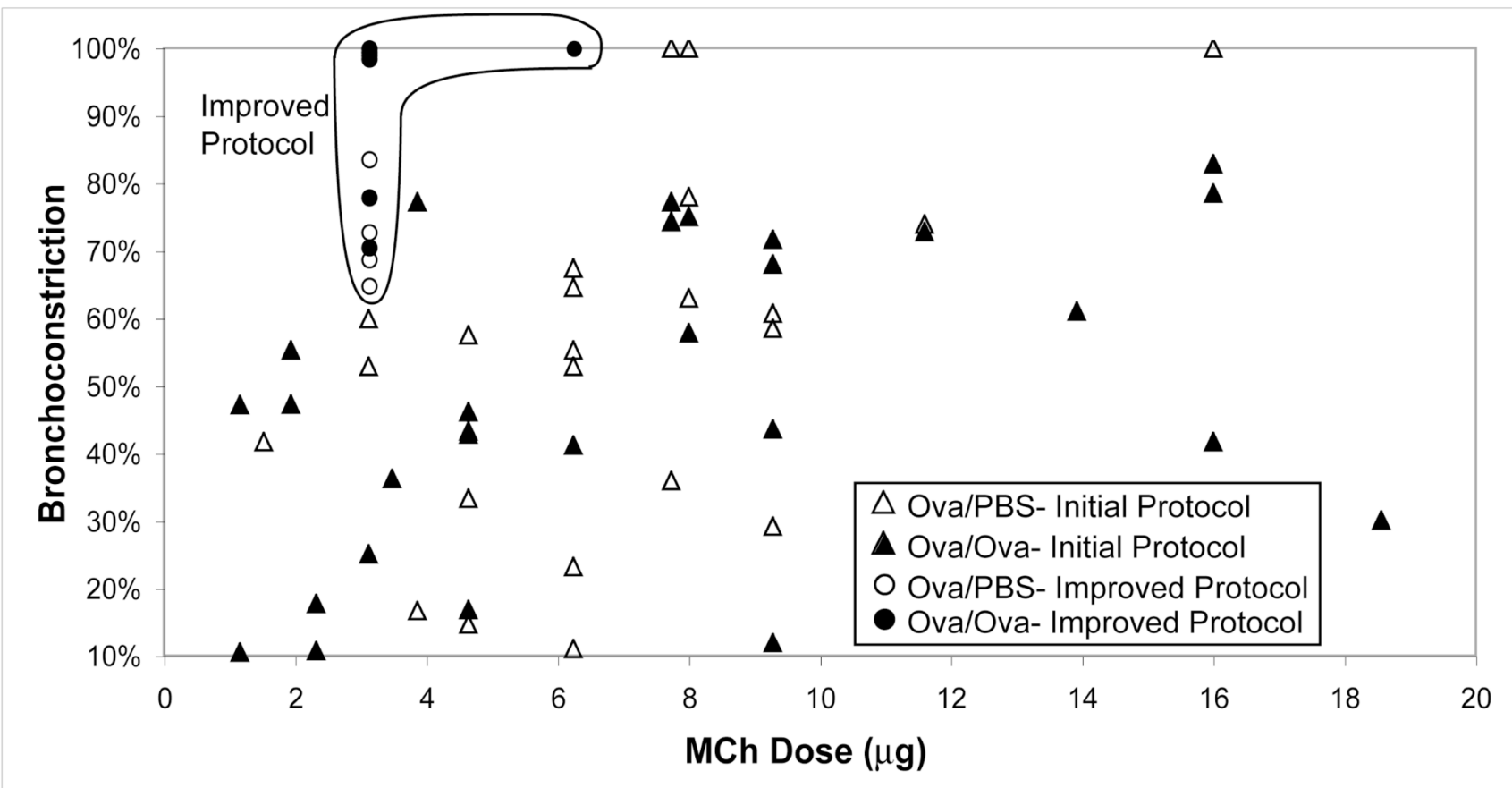

Figure 12.

Comparison of bronchoconstriction observed in the medial lobe bronchus between the initial and improved MCh delivery protocols. Constriction observed under the initial MCh protocol is shown by the triangles (open for PBS, closed for Ova) at a wide range of doses and exhibiting a high degree of variability. Constriction observed under the improved MCh protocol is shown by the circles (open for PBS and solid for Ova) depicting a much higher, less variable degree of bronchoconstriction at lower MCh doses. 


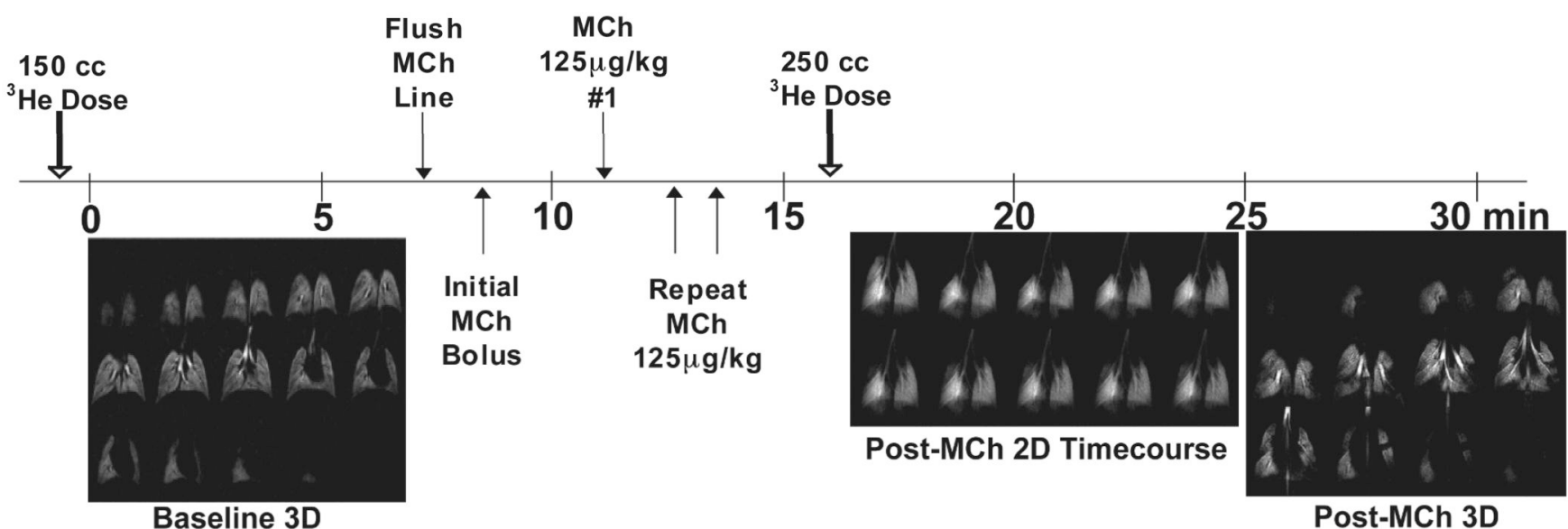

Figure 13.

Improved protocol for MCh delivery and imaging. A baseline 3D image is obtained prior to MCh challenge using a $150 \mathrm{~mL}$ dispense of hyperpolarized ${ }^{3} \mathrm{He}$ gas. Then, the extension tubing is filled and flushed with fresh MCh solution and an initial bolus of $\sim 200 \mu 1$ is directed to the animal to fill the catheter inlet line and catheter with fresh MCh. Shortly thereafter, a series of $125 \mu \mathrm{g} / \mathrm{kg}$ bolus injections are repeated until a reproducible drop in HR is obtained. Then, a $2 \mathrm{D}$ time-course series of ${ }^{3} \mathrm{He}$ images is obtained consisting of 10 frames taken every $12 \mathrm{~s}$ and a $125 \mu \mathrm{g} / \mathrm{kg} \mathrm{MCh}$ bolus delivered after the first baseline frame. This is immediately followed by acquisition of a 3D image from the same $250 \mathrm{~mL}$ dispense of hyperpolarized ${ }^{3} \mathrm{He}$ gas to display persistent defects in greater detail. 
TOP
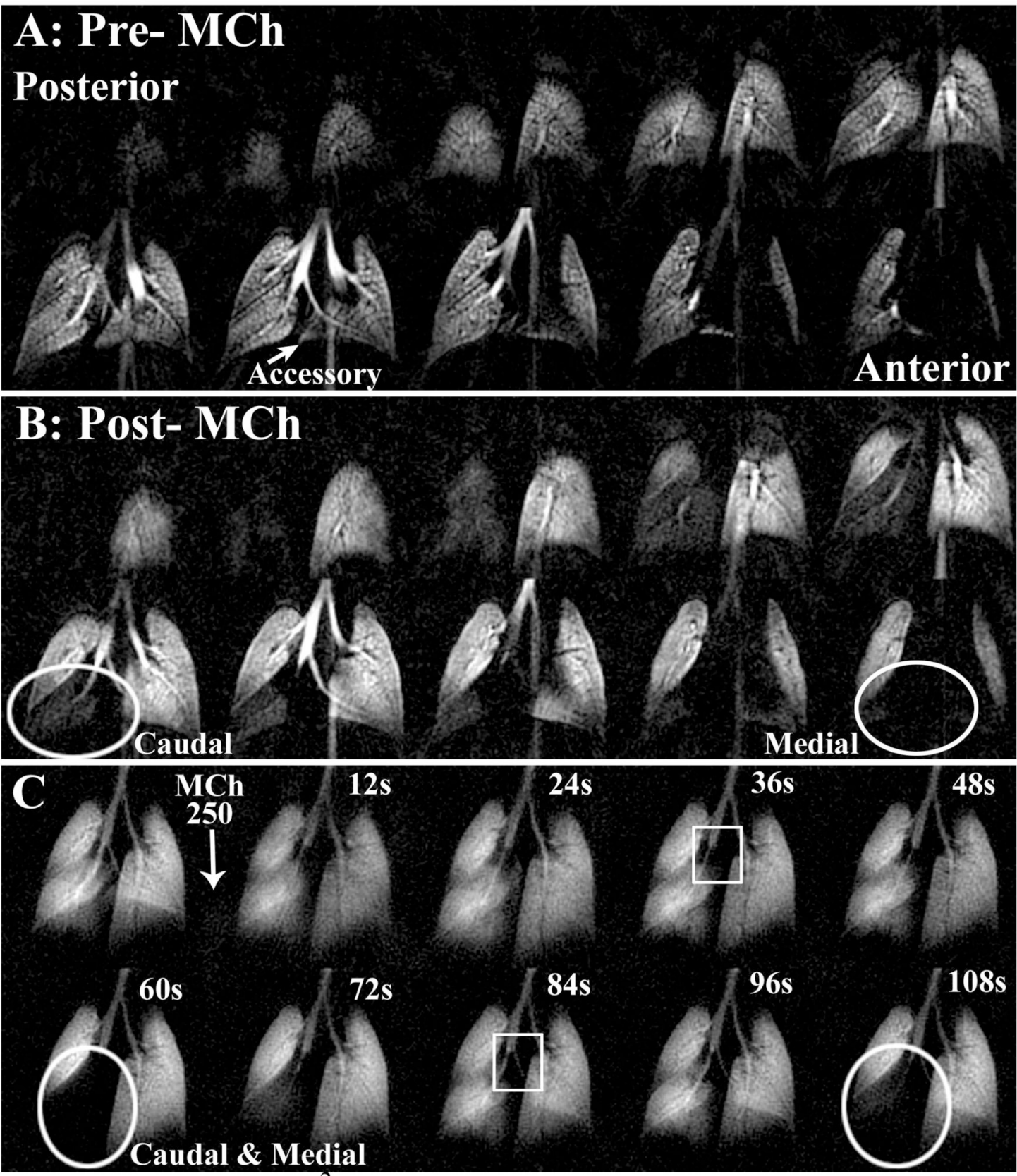

Figure 14.

$3 \mathrm{D}$ and $2 \mathrm{D}{ }^{3} \mathrm{He}$ datasets using the improved protocol in an Ova/Ova mouse. (A) Baseline 3D images and (B) 3D images following a $250 \mu \mathrm{g} / \mathrm{kg}$ MCh challenge, in which ventilation defects and bronchoconstriction are visible on the successive posterior to anterior slices. (C) 2D timecourse images taken at $12 \mathrm{~s}$ intervals before and after MCh challenge. Corresponding whole lobar medial and caudal lobe ventilation defects are circled on the 3D and 2D images. The disappearance and subsequent reappearance of the ventilation to the accessory lobe is noted by boxes at the $36 \mathrm{~s}$ and $84 \mathrm{~s}$ post-MCh timepoints, respectively. We note that although the preand post-MCh 3D images were separated in time by the 2D time-course series, they are placed together in this figure to aid in their comparison. 
Table 1

The various MCh bolus injections and/or continuous infusion rates applied to each mouse are specified. Numbers in parentheses indicate separate boluses of the same volume. The mice are separated by treatment group using either the initial or improved MCh delivery method.

\begin{tabular}{|c|c|c|c|}
\hline & Mouse & Infusion Rates (mL/hr) & Bolus Amounts $(\mu \mathrm{L})$ \\
\hline \multirow[t]{8}{*}{ Control- Initial Protocol } & 1 & & $78(2)$ \\
\hline & 2 & & 78 \\
\hline & 3 & & $78(4)$ \\
\hline & 4 & $0.5,1,2,3$ & \\
\hline & 5 & $0.3,0.6,1.2,2.4$ & 100 \\
\hline & 6 & $1.2,2.4$ & $200(2)$ \\
\hline & 7 & $1.2,2$ & $19,39,100$ \\
\hline & 8 & $1.2,2.4$ & $39,78,100$ \\
\hline \multirow[t]{8}{*}{ Ova/Ova- Initial Protocol } & 1 & $0.5,2$ & \\
\hline & 2 & $0.5,1,2,3$ & \\
\hline & 3 & $0.3,0.6,0.9,1.2$ & \\
\hline & 4 & & 100 \\
\hline & 5 & $0.3,1.2,2.4,3.6$ & 200 \\
\hline & 6 & $0.3,0.6,1.2,2.4$ & 200 \\
\hline & 7 & $0.6,1.2,2.4,4.8$ & 200 \\
\hline & 8 & $1.2,2.4$ & $39,78,100$ \\
\hline \multirow[t]{3}{*}{ Control- Improved Protocol } & 1 & & $39(2)$ \\
\hline & 2 & & 39 \\
\hline & 3 & & 39 \\
\hline \multirow[t]{6}{*}{ Ova/Ova- Improved Protocol } & 1 & & 39,78 \\
\hline & 2 & & 39 \\
\hline & 3 & & 39 \\
\hline & 4 & & 39 \\
\hline & 5 & & 39 \\
\hline & 6 & & 39 \\
\hline
\end{tabular}

